\title{
Mediated Growth of Carbon Nitride Films via Spray-Coated Seeding Layers for Photoelectrochemical Applications
}

\section{Ayelet Tashakory, Neeta Karjule, Liel Abisdris, Michael Volokh, Menny Shalom*}

\author{
A. Tashakory, Dr. N. Karjule, L. Abisdris, Dr. M. Volokh, Prof. M. Shalom* \\ Department of Chemistry and Ilse Katz Institute for Nanoscale Science and Technology Ben- \\ Gurion University of the Negev, Beer-Sheva 8410501, Israel. \\ E-mail: mennysh@bgu.ac.il
}

Keywords: carbon nitride, water splitting, photoelectrochemical cells, spray coating

Polymeric carbon nitride $(\mathrm{CN})$ has emerged as a promising semiconductor in photoelectrochemical devices, thanks to its unique electronic and catalytic properties, low price, stability in various chemical environments, and benign nature. Decent progress in the deposition and growth of $\mathrm{CN}$ layers on substrates has been achieved using several deposition and growth methods; however, the properties of the layer, including the quality of its contact with the substrate and its structural properties, are still largely dependent on the surface properties of said substrate. Here, we introduce a new approach in which a spray-coated seeding layer composed of $\mathrm{CN}$ monomers directs the growth of a homogenous, thick $\mathrm{CN}$ layer on a substrate by calcination at high temperature in the presence of melamine vapor. Uniform $\mathrm{CN}$ layers with strong adhesion to the substrate were obtained. The influence of the seeding layer and the vapor composition on the photoelectrochemical, optical, and structural properties was studied in detail. The best-performing electrode, based on urea as the seeding layer, demonstrates good activity as a photoanode in photoelectrochemical cells, reaching up to $300 \mu \mathrm{A} \mathrm{cm} \mathrm{cm}^{-2}$ in the presence of a hole scavenger. 


\section{WILEY-VCH}

\section{Introduction}

Polymeric carbon nitride materials (CNs) have emerged as low-cost, chemically stable photoand electro-catalysts for various reactions such as water splitting, $\mathrm{CO}_{2}$ reduction, and other organic transformation reactions. ${ }^{[1-10]}$ In the last few years, efforts to integrate carbon nitride films into photoelectronic and photoelectrochemical devices have increased, motivated by the unique photophysical properties of carbon nitride (energy band positions and tunable bandgap) and its stability under harsh chemical environments. ${ }^{[11-12]}$ However, the deposition/growth of a CN layer in intimate contact with the substrate remains an ongoing challenge. ${ }^{[13-15]}$ To this end, several gas-phase-based methods to grow CN layers on a substrate have been developed: chemical vapor deposition (CVD), ${ }^{[16-17]}$ thermal vapor condensation (TVC), ${ }^{[18-21]}$ microwaveassisted condensation, ${ }^{[22]}$ alongside others. However, in all scenarios, one of the main bottlenecks for the growth of a homogenous and firmly attached layer is the poor interaction of $\mathrm{CN}$ with the surface of the substrate. This is especially the case for methods involving the adsorption of a gas-phase reactant (e.g., CVD) since solid-gas interactions between the substrate and the $\mathrm{CN}$ monomer are required for the reaction to occur. ${ }^{[23]}$ Therefore, the $\mathrm{CN}$ coatings obtained so far have mostly consisted of thin, poorly attached layers.

One approach to directing the growth of materials by a gas-phase reaction is to use a seeding layer to facilitate the nucleation process. ${ }^{[24-27]}$ Furthermore, a thicker layer can be prepared by this approach, owing to the large roughness induced by the seeding layer compared to a flat substrate. For a controlled gas-phase growth of a $\mathrm{CN}$ layer on a substrate, a homogenous seeding layer of controlled thickness consisting of $\mathrm{CN}$ monomers should be deposited before the thermal condensation. Spray coating is a facile, repeatable, and large-scale method to coat a substrate with a wide diversity of molecules and materials. ${ }^{[28-29]}$ In this technique, a liquid is atomized into a mist of even micron-sized droplets using ultrasonic vibrations in the nozzle; it can then be easily and controllably deposited as a layer on a variety of (possibly heated) substrates. 


\section{WILEY-VCH}

Herein we report the use of spray coating to deposit a seeding layer of urea and other $\mathrm{CN}$ monomers, for the direct growth of $\mathrm{CN}$ films on substrates by calcination in the presence of melamine vapor. The seeding layer provides nucleation sites promoting the growth of the $\mathrm{CN}$ film in the form of a homogenous layer in intimate contact with the substrate, thus improving the photoelectronic properties of the electrode. The morphology, structural properties, and optical properties of the obtained $\mathrm{CN}$ films were investigated. The photoelectrochemical performance was measured for a model water-splitting photoelectrochemical cell (PEC) setup; specifically, hydrogen evolution reaction in the presence of a hole scavenger was measured, which accords with the United Nation's sustainable development goals as a source of affordable and clean energy. ${ }^{[30-34]}$

\section{Results and Discussion}

\subsection{Preparation and Characterization of Urea Films}

The synthetic route is illustrated in Figure 1a. The first step is the deposition of a CN-precursor seeding layer of controlled thickness. Here, an aqueous urea solution $\left(375 \mathrm{~g} \mathrm{~L}^{-1}\right.$; the solubility of urea at room temperature is $\left.1096 \mathrm{~g} \mathrm{~L}^{-1}\right)^{[35]}$ was sprayed on fluorine-doped tin oxide (FTO) coated glass using an ultrasonic spray coater, forming a uniform layer of urea on the FTO. The spraying process includes a variable number of repetitive spray cycles; several films were prepared and labeled as $\mathrm{U}_{x}$, where $x$ represents the number of spray cycles: $5,10,50$, or 100 . The X-ray diffraction (XRD) patterns of $U_{10}$ and urea powder exhibit similar features (Figure 1b); the additional diffraction signals for $U_{10}$ are attributed to the FTO substrate. The Fouriertransform infrared (FTIR) spectra of $\mathrm{U}_{10}$ and urea powder show similar N-H vibrations in the range of $3230-3410 \mathrm{~cm}^{-1}$, as well as a $\mathrm{C}=\mathrm{O}$ stretching band at $\sim 1660 \mathrm{~cm}^{-1}$, which further confirms the successful deposition of urea on the FTO (Figure S1). Top-view and crosssectional scanning electron microscopy (SEM) images disclose the morphology of the obtained $\mathrm{U}_{x}$ films: as the number of spray cycles increases, the layer becomes thicker and rougher (Figure 1c and S2). 


\section{WILEY-VCH}

\subsection{Preparation and Characterization of $\mathrm{CN}$ Films}

The calcination of the $\mathrm{U}_{x}$ films in the presence of melamine powder $(0.5 \mathrm{~g}$ at the bottom of a closed, but not sealed, reaction glass tube at $550{ }^{\circ} \mathrm{C}$ under $\mathrm{N}_{2}$ atmosphere for 4 hours) led to the formation of $\mathrm{CN}$ electrodes (labeled as $\mathrm{CN}-\mathrm{U}_{x} \mathrm{M}_{0.5}$ ). During the thermal treatment, the melamine sublimes, and the vapor is deposited on the urea-coated FTO substrate, ${ }^{[24]}$ where the urea coating serves as a seeding layer for the growth of the $\mathrm{CN}$. Motivated by the high photocurrent density of $\mathrm{CN}-\mathrm{U}_{10} \mathrm{M}_{0.5}$ under operational PEC conditions (as will be shown later), we prepared another electrode by spraying 10 cycles of urea solution as a seeding layer, followed by calcination in the presence of $1.0 \mathrm{~g}$ of melamine (labeled as $\mathrm{CN}-\mathrm{U}_{10} \mathrm{M}_{1}$ ) instead of the $0.5 \mathrm{~g}$ that was used in all other cases.

To evaluate its importance in the formation of the final $\mathrm{CN}$ film, we performed a similar calcination process in the absence of the seeding layer (namely, the $\mathrm{CN}$ film was created by deposition of melamine vapor on bare FTO, labeled as $\mathrm{CN}-\mathrm{M}_{0.5}$ ). Without the seeding layer, the process resulted in incomplete coverage of the substrate by the $\mathrm{CN}$ film. Indeed, top-view and cross-sectional SEM images show that $\mathrm{CN}-\mathrm{M}_{0.5}$ consists of a patchy, uneven distribution of CN structures that only partially covers the FTO surface (Figure $2 \mathbf{a}-\mathbf{b}$ ). In contrast, while $\mathrm{CN}-\mathrm{U}_{5} \mathrm{M}_{0.5}$ has a similar morphology to that of $\mathrm{CN}-\mathrm{M}_{0.5}$, it provides better coverage of the substrate (Figure S3a-b). This difference proves the critical role of the seeding layer in the formation of a uniform $\mathrm{CN}$ film on the FTO. We also performed the same calcination process in the absence of melamine powder in the reaction tube; most of the urea film sublimed during calcination, and no substantial CN film was formed on the FTO. Therefore, we conclude that both the seeding layer and the melamine vapor are essential for the growth of a CN layer that fully covers the FTO.

The top-view and cross-sectional SEM images of $\mathrm{CN}-\mathrm{U}_{x} \mathrm{M}_{0.5}$ and $\mathrm{CN}-\mathrm{U}_{10} \mathrm{M}_{1}$ (Figure 2c-d and S3) reveal interesting outcomes. The top-view SEM images of $\mathrm{CN}-\mathrm{U}_{10} \mathrm{M}_{0.5}, \mathrm{CN}-$ $\mathrm{U}_{50} \mathrm{M}_{0.5}, \mathrm{CN}-\mathrm{U}_{100} \mathrm{M}_{0.5}$, and $\mathrm{CN}-\mathrm{U}_{10} \mathrm{M}_{1}$ all show uniform coating of the FTO. However, their 


\section{WILEY-VCH}

cross-sectional SEM images reveal differences: $\mathrm{CN}-\mathrm{U}_{10} \mathrm{M}_{0.5}$ is very compact and has the fullest contact to the FTO and a uniform layer thickness, whereas the contact of $\mathrm{CN}-\mathrm{U}_{50} \mathrm{M}_{0.5}$ and $\mathrm{CN}$ $\mathrm{U}_{100} \mathrm{M}_{0.5}$ with the FTO is less homogenous. Besides, $\mathrm{CN}-\mathrm{U}_{10} \mathrm{M}_{1}$ shows significant variations in its thickness, which is likely due to an excess of melamine powder during calcination.

The XRD patterns of the obtained CN electrodes (Figure 3a) exhibit two typical CN signals corresponding to an in-plane (100) diffraction at $12.8^{\circ}$ and an interplanar stacking (002) diffraction at 27.6.$^{\circ}{ }^{[36]}$ The FTIR spectra of the CN electrodes (Figure S4) show signals in the $1100-1700 \mathrm{~cm}^{-1}$ range that correspond to $\mathrm{C}-\mathrm{N}$ heterocycles stretching modes. The peaks at $\sim 800 \mathrm{~cm}^{-1}$ are attributed to the breathing vibration of the heptazine units in $\mathrm{CN}$ films, whereas the broad bands at $\sim 3000-3600 \mathrm{~cm}^{-1}$ match the stretching vibration of $\mathrm{N}-\mathrm{H}$ in the amino groups resulting from incomplete polymerization. The X-ray photoelectron spectroscopy (XPS) spectra of $\mathrm{CN}-\mathrm{U}_{10} \mathrm{M}_{0.5}$ (Figure S5) confirm the successful growth of $\mathrm{CN}$ films. The $\mathrm{C} 1 \mathrm{~s}$ spectrum presents three peaks located at $284.9 \mathrm{eV}, 288.0 \mathrm{eV}$, and $289.4 \mathrm{eV}$, which correspond to $\mathrm{C}-\mathrm{C}$ from the carbonaceous environment, $\mathrm{N}-\mathrm{C}=\mathrm{N}$ coordination, and $\mathrm{O}-\mathrm{C}=\mathrm{O}$, respectively, with the latter possibly resulting from partial oxidation of the $\mathrm{CN}$ film. ${ }^{[37]}$ The N1s spectrum reveals three peaks located at $398.4 \mathrm{eV}, 399.5 \mathrm{eV}$, and $400.8 \mathrm{eV}$, attributed to $\mathrm{C}=\mathrm{N}-\mathrm{C}, \mathrm{N}-(\mathrm{C})_{3}$, and $\mathrm{N}-\mathrm{H}$, respectively. Hence, the XRD, FTIR, and XPS results confirm the formation of tri-striazine-based $\mathrm{CN}$.

The UV-vis absorbance spectra of all CN electrodes exhibit similar features except that of $\mathrm{CN}-\mathrm{M}_{0.5}$, which displays the highest transmittance, owing to the uneven appearance of $\mathrm{CN}$ $\mathrm{M}_{0.5}$ (Figure 3b). A Tauc plot analysis (Figure 3c) reveals an optical bandgap in the 2.60-2.64 eV range for the $\mathrm{CN}-\mathrm{U}_{x} \mathrm{M}_{y}$ films, as expected for $\mathrm{CN}$ materials. ${ }^{[38]}$ The $\mathrm{CN}-\mathrm{U}_{10} \mathrm{M}_{0.5}$ film has the narrowest estimated bandgap (2.60 eV). It also exhibits the lowest photoluminescence (PL) intensity (Figure 3d), suggesting nonradiative recombination paths of photogenerated electronhole pairs caused by surface states. 


\section{WILEY-VCH}

\subsection{Adhesion Test}

To evaluate the mechanical stability and adhesion of the $\mathrm{CN}$ films to the FTO, we covered $\mathrm{CN}-$ $\mathrm{U}_{10} \mathrm{M}_{0.5}, \mathrm{CN}-\mathrm{M}_{0.5}$, and $\mathrm{CN}-\mathrm{U}_{10} \mathrm{M}_{1}$ with scotch tape and placed a heavy object (ca. $1.5 \mathrm{~kg}$ ) on top of each sample for two hours (Figure S6). Removal of the scotch tape revealed that $\mathrm{CN}-$ $\mathrm{U}_{10} \mathrm{M}_{0.5}$ largely remained uniform, whereas $\mathrm{CN}-\mathrm{M}_{0.5}$ was affected to a greater extent, clearly illustrating the benefit of using a seeding layer. $\mathrm{CN}-\mathrm{U}_{10} \mathrm{M}_{1}$ peeled off partially, probably because of the thickness differences in different areas of the electrode, as its cross-sectional SEM image shows (Figure S3h).

\subsection{Versatility of the Method}

The deposition of a urea seeding layer by spray coating followed by the growth of a CN film from melamine vapor during calcination was also achieved on a glass slide and carbon cloth (Figure S7a-c). A similar procedure was successfully carried out on a $9 \mathrm{~cm} \times 1.2 \mathrm{~cm}$ FTO slide to show the applicability of the method to larger surfaces (Figure S7d). Furthermore, for the sake of example, we successfully used thiourea and alanine instead of urea as the seeding layer (Figure S7e and S7f, respectively) and substituted thiourea for melamine as the precursor that undergoes sublimation in the test tube (Figure S7g). These proof-of-principle results indicate that the $\mathrm{CN}$ electrodes can be prepared from different monomers and that the seeding layer promotes the growth of a $\mathrm{CN}$ film regardless of the type and size of the substrate. However, further optimization is needed for each system.

\subsection{PEC performance of the $\mathrm{CN}$ Electrodes}

The activity of the $\mathrm{CN}$ electrodes as water-splitting photoanodes was tested in a standard threeelectrode system. Chronoamperometric measurements of the $\mathrm{CN}$ electrodes were performed at 1.23 V vs. RHE in $0.1 \mathrm{M} \mathrm{KOH}$ under 1-sun front- and back-side illumination (Figure 4a and S8). The highest photocurrent density ( $c a .110 \mu \mathrm{A} \mathrm{cm}{ }^{-2}$ ) was obtained using a $\mathrm{CN}-\mathrm{U}_{10} \mathrm{M}_{0.5}$ photoelectrode under back-side illumination. We ascribe this to the electron diffusion length being the limiting factor in charge separation and transport. ${ }^{[39]}$ Additional chronoamperometry 


\section{WILEY-VCH}

measurements were conducted in the presence of triethanolamine (TEOA) as a hole scavenger $(10 \%(\mathrm{v} / \mathrm{v})$ TEOA in $0.1 \mathrm{M} \mathrm{KOH})$ to test the efficiency of electron transport, assuming most photogenerated holes are consumed by TEOA (Figure 4b and S9). Under these conditions, both photocurrent density values and stability were improved in all the $\mathrm{CN}$ electrodes, thanks to the improved hole extraction, which hinders the recombination of photogenerated electron-hole pairs and the self-oxidation of the CN layer. Linear sweep voltammetry (LSV) curves in the dark and under 1-sun back-side illumination (Figure 4c) disclose a low onset potential of 0.17 V vs. RHE for $\mathrm{CN}-\mathrm{U}_{10} \mathrm{M}_{0.5}$. All the $\mathrm{CN}$ electrodes exhibited a linear increase in photocurrent density with increased potential — a typical PEC behavior — and a sharp increase in current at approximately $1.7 \mathrm{~V}$ vs. RHE attributed to electrocatalytic water oxidation.

The charge transfer efficiency of $\mathrm{CN}-\mathrm{U}_{10} \mathrm{M}_{0.5}$ reached up to $53 \%$ at $1.6 \mathrm{~V}$ vs. RHE (Figure S10). Incident photon-to-current conversion efficiency (IPCE) measurements of CN$\mathrm{U}_{10} \mathrm{M}_{0.5}$ were performed at $1.23 \mathrm{~V} v s$. RHE in both $0.1 \mathrm{M} \mathrm{KOH}$ and $10 \%(\mathrm{v} / \mathrm{v})$ TEOA in $0.1 \mathrm{M}$ $\mathrm{KOH}$ (Figure 4d). The highest efficiency was achieved at $380 \mathrm{~nm}$ in both cases; the presence of a hole scavenger improved the IPCE value from $1.7 \%$ to $3.9 \%$. In addition, $\mathrm{CN}-\mathrm{U}_{10} \mathrm{M}_{0.5}$ showed a good stability in the presence of TEOA, with a photocurrent value of $c a .60 \mu \mathrm{A} \mathrm{cm}{ }^{-2}$ even after $16 \mathrm{~h}$ of continuous illumination (Figure S11). Additional chronoamperometric measurements of $\mathrm{CN}-\mathrm{U}_{10} \mathrm{M}_{0.5}$ were performed at $1.23 \mathrm{~V} v s$. RHE in a neutral aqueous solution (0.1 M phosphate buffer, $\mathrm{pH} \approx 7$ ) under 1-sun front- and back-side illumination (Figure S12). Under these conditions, a lower photocurrent density $\left(c a .65 \mu \mathrm{A} \mathrm{cm}^{-2}\right)$ was obtained compared to the photoanode's performance in $0.1 \mathrm{M} \mathrm{KOH}$; no apparent change in stability was observed. Using Mott-Schottky analysis of the electrodes (Figure S13) and the optical band gaps (Figure 3c), we calculated the energy diagram presented in Figure S14, which shows the band positions of all the $\mathrm{CN}$ electrodes. Moreover, despite morphological changes of the $\mathrm{CN}$ film following PEC measurements in alkaline conditions, its contact with the substrate remained quite homogenous (Figure S15). The XRD patterns of $\mathrm{CN}-\mathrm{U}_{10} \mathrm{M}_{0.5}$ before and after PEC 


\section{WILEY-VCH}

measurements do not exhibit any significant difference (Figure S16), while an EDS analysis of the photoanode post-PEC measurements reveals a minor increase in oxygen quantity, suggesting oxidation of CN film during the measurements (Figure S17 and Table S1).

The measured PEC performances of the various $\mathrm{CN}$ photoelectrodes, together with the morphology analysis of the urea films before calcination and the corresponding $\mathrm{CN}$ photoelectrodes, show that a seeding layer $(\mathrm{ca} .12 \mu \mathrm{m})$ is of great benefit for the formation of a homogenous $\mathrm{CN}$ film firmly attached to the substrate.

\section{Conclusions}

To conclude, we reported a facile and scalable method to grow a homogenous $\mathrm{CN}$ layer on a substrate, with good adhesion, by providing nucleation sites for the growth of $\mathrm{CN}$ from the gas phase. To do so, we coated the substrate with $\mathrm{CN}$ precursors, using a spray coating technique before the thermal condensation. Our results indicate that the seeding layer promotes the growth of a uniform CN film regardless of the type and size of the substrate. The influence of the spray coating parameters (composition, thickness, and solvent) and the vapor content were studied in detail and correlated with the structural, photophysical, and photoelectrochemical properties of the CN layer. The new electrodes exhibit good performance as photoanodes in photoelectrochemical cells, i.e., low onset potential, high photocurrent density, and moderate photostability. This approach facilitates the growth of $\mathrm{CN}$ on various substrates with controlled properties; its extension to other $\mathrm{CN}$ and metal-free materials on various substrates with controlled properties should accelerate their integration into photoelectrochemical devices.

\section{Experimental Section}

Materials:

All reagents and solvents were used as received from their respective commercial vendors, without further purification: urea (98\%) and triethanolamine (TEOA, 99\%) from Glentham; thiourea (99\%) from Acros Organics; L-alanine (>95\%) from Fisher Bioreagents; melamine 


\section{WILEY-VCH}

(99\%) from Sigma-Aldrich. $\mathrm{KOH}(85 \%)$ and $\mathrm{Na}_{2} \mathrm{SO}_{4}$ (99\%) from Loba-Chemie; $\mathrm{Na}_{2} \mathrm{HPO}_{4}$ $(98+\%)$ and $\mathrm{NaH}_{2} \mathrm{PO}_{4}(96 \%)$ from Alfa Aesar; acetone (99.8\%) and ethanol (absolute, 99.9\%) from Bio-Lab Chemicals. Deionized water $\left(18.2 \mathrm{M} \Omega \mathrm{cm}\right.$ resistivity at $25{ }^{\circ} \mathrm{C}$, purified using a Millipore Direct-Q3 system) was used for all aqueous solutions. Fluorine-doped tin oxide (FTO)-coated glass (12-14 $\Omega \mathrm{sq}^{-1}$ ) was purchased from Xop Glass company, Spain. Before use, the FTO was cut into rectangular pieces $(1.3 \mathrm{~cm} \times 2.5 \mathrm{~cm})$ and sonicated with an aqueous detergent solution (Alconox, $1 \% \mathrm{~m} / \mathrm{v}$ ), acetone, and ethanol successively, for $15 \mathrm{~min}$ each, then dried in an air oven at $60^{\circ} \mathrm{C}$.

Preparation of urea/FTO films:

First, an aqueous urea solution $\left(375 \mathrm{~g} \mathrm{~L}^{-1}\right)$ was prepared by dissolving $15 \mathrm{~g}$ of urea in $40 \mathrm{~mL}$ of water and then shaking the mixture for $15 \mathrm{~min}$. Next, the solution was sprayed on an FTO substrate heated to $45^{\circ} \mathrm{C}$ using a Sono-Tek ExactaCoat ultrasonic spray coater, with a varying number of spray cycles $(5,10,50$, or 100$)$ and the following constant spray parameters: shaping air pressure of $0.5 \mathrm{psi}(\mathrm{ca} .3 .5 \mathrm{kPa})$, dwell time of $10 \mathrm{~s}$ between spray cycles, and distance of $4.0 \mathrm{~cm}$ between the spray nozzle and the FTO. Finally, the urea/FTO films were dried in an air oven at $60{ }^{\circ} \mathrm{C}$ (these films are denoted as $\mathrm{U}_{x}, x$ being the number of spray cycles). The choice of solvent and $\mathrm{CN}$ precursor to be sprayed is determined mainly according to solubility — urea was chosen to be deposited as a seeding layer due to its high solubility in water, which enables the formation of uniform films with controlled thickness by the spray coater. Preparation of CN films:

Each piece of urea/FTO was inserted into a glass test tube $(16 \mathrm{~mm}$ diameter $\times 100 \mathrm{~mm}$ length $)$ filled with the chosen amount of melamine powder $(0.5 \mathrm{~g}$ or $1.0 \mathrm{~g})$ at its closed end. The tube was purged with $\mathrm{N}_{2}$ for 1 min and closed with an $\mathrm{Al}$ foil. Lastly, the tube was submitted to a calcination process of $4 \mathrm{~h}$ at $550{ }^{\circ} \mathrm{C}$ with a heating ramp of $4.2{ }^{\circ} \mathrm{C} \mathrm{min}-1$ under $\mathrm{N}_{2}$ atmosphere to yield $\mathrm{CN}$ electrodes denoted as $\mathrm{CN}-\mathrm{U}_{x} \mathrm{M}_{y}$, where $y$ is the mass of melamine in the tube. 


\section{WILEY-VCH}

For the evaluation of the versatility of the method, we explored different materials: the growth of CN films on glass and carbon cloth substrates was achieved similarly to that of CN$\mathrm{U}_{10} \mathrm{M}_{0.5}$, i.e., deposition of a seeding layer by 10 spraying cycles of urea, then calcination in the presence of $0.5 \mathrm{~g}$ of melamine. For the growth of a $\mathrm{CN}$ film on a $9 \mathrm{~cm} \times 1.2 \mathrm{~cm} \mathrm{FTO} \mathrm{slide,} \mathrm{the}$ procedure for the preparation of $\mathrm{CN}-\mathrm{U}_{10} \mathrm{M}_{1}$ was applied, only in a larger glass test tube $(16 \mathrm{~mm}$ diameter $\times 150 \mathrm{~mm}$ length). The deposition of thiourea and L-alanine as seeding layers was achieved by spraying 10 cycles of aqueous thiourea $\left(150 \mathrm{~g} \mathrm{~L}^{-1}\right)$ or aqueous L-alanine $\left(125 \mathrm{~g} \mathrm{~L}^{-}\right.$ $\left.{ }^{1}\right)$ solution, respectively.

\section{Characterization:}

The morphology of the samples was characterized using a scanning electron microscope (SEM, FEI VERIOS 460L) operated at $3.5 \mathrm{kV}, 25 \mathrm{pA}$, and using an Everhart-Thornley secondary electron detector (ETD); the samples were sputtered with $\sim 7 \mathrm{~nm}$ gold before analysis. Energy dispersive X-ray spectroscopy (EDS) was performed using the aforementioned microscope, operated at $6 \mathrm{kV}$ with a probe current of $13 \mathrm{nA}$. X-ray diffraction (XRD) patterns were measured using a PANalytical Empyrean diffractometer (equipped with an X'celerator position-sensitive detector) with a scanning time of $\sim 7 \mathrm{~min}$ for a $2 \theta$ range of $5-60^{\circ}$, using $\mathrm{Cu} \mathrm{K} \alpha$ radiation $(\lambda=$ $1.54178 \AA$ ) — operation parameters: $40 \mathrm{kV}, 30 \mathrm{~mA}$. Fourier transformed infrared (FTIR) spectra were collected on a Thermo Scientific Nicolet iS5 using a diamond iD7 ATR. The chemical states of key elements were deduced from X-ray photoelectron spectroscopy (XPS) measurements conducted on a Thermo Fisher Scientific ESCALAB 250 using monochromated K $\alpha$ X-rays; all the binding energies in the XPS spectra were calibrated using the C 1s peak at $284.8 \mathrm{eV}$. UV-vis spectra were recorded on a Cary 100 spectrophotometer equipped with a diffuse reflectance accessory (DRA) in both transmittance $(T)$ and reflectance $(R)$ modes; the absorbance was calculated as: $100-T-R(\%)$. A Horiba Scientific FluroMax 4 fluorimeter 


\section{WILEY-VCH}

was used to collect photoluminescence (PL) spectra, with an excitation wavelength of $\lambda_{\mathrm{ex}}=390$ nm.

Photoelectrochemical measurements:

All photoelectrochemical measurements were performed using a three-electrode system with a Pt plate $\left(1.0 \mathrm{~cm}^{2}\right)$ and $\mathrm{Ag} / \mathrm{AgCl}$ (saturated $\mathrm{KCl}$ ) as the counter and reference electrodes, respectively. The electrolyte was either $0.1 \mathrm{M} \mathrm{KOH}$ aqueous solution $(\mathrm{pH} \approx 13), 0.1 \mathrm{M} \mathrm{KOH}$ solution containing $10 \%(\mathrm{v} / \mathrm{v} \%)$ TEOA or phosphate buffer $(\mathrm{pH} \approx 7)$. All potential values versus $\mathrm{Ag} / \mathrm{AgCl}$ were converted to values versus reversible hydrogen electrode (RHE) using the Nernst equation at room temperature:

$$
V_{\mathrm{RHE}}=V_{\mathrm{Ag} / \mathrm{AgCl}}+0.059 \times \mathrm{pH}+0.197(\mathrm{~V})
$$

Chronoamperometry and linear sweep voltammetry (LSV) measurements were conducted using an Ivium potentiostat (Vertex.1A). Photocurrent density was measured at a bias potential of $1.23 \mathrm{~V} v s$. RHE under 1-sun illumination (power density of $100 \mathrm{~mW} \mathrm{~cm}^{-2}$ ) supplied by an LCS-100 solar simulator (calibrated using a Newport 919P power meter). LSV measurements were performed in the dark and under 1-sun illumination in the range of $0-1.8 \mathrm{~V} v$ s. RHE. Incident photon-to-current conversion efficiency (IPCE) and Mott-Schottky measurements were performed using an Autolab potentiostat (Metrohm, PGSTAT302N). IPCE measurements were performed under 1-sun illumination supplied by a Newport 94011A solar simulator equipped with an air mass AM1.5G filter and calibrated using a Newport 919P power meter. Values were calculated using:

$$
\operatorname{IPCE}(\%)=\frac{J\left(\mathrm{~A} \mathrm{~cm}^{-2}\right) \cdot 1240}{\lambda(\mathrm{nm}) \cdot I\left(\mathrm{~W} \mathrm{~cm}^{-2}\right)} \cdot 100 \%
$$

Where $J$ is the photocurrent, $\lambda$ is the wavelength of the incident monochromic light, which is controlled by different optical bandpass filters (Newport 10BBPF10 series) with a center wavelength of $380 \mathrm{~nm}, 400 \mathrm{~nm}, 420 \mathrm{~nm}, 440 \mathrm{~nm}, 460 \mathrm{~nm}$, and $480 \mathrm{~nm}$, and $I$ is the light power density. 


\section{WILEY-VCH}

The charge transfer efficiency was calculated using:

$$
\eta(\%)=\frac{J_{\mathrm{KOH}}}{J_{\mathrm{TEOA}}} \cdot 100 \%
$$

$J_{\mathrm{KOH}}$ is the photocurrent density obtained in $0.1 \mathrm{M} \mathrm{KOH}$ aqueous solution, while $J_{\mathrm{TEOA}}$ is the photocurrent density obtained in $0.1 \mathrm{M} \mathrm{KOH}$ containing $10 \%(\mathrm{v} / \mathrm{v})$ TEOA. We assume that the extraction rate of photogenerated holes in the system is $100 \%$ after the addition of the hole scavenger. Mott-Schottky measurements were carried out in $1.0 \mathrm{M} \mathrm{Na}_{2} \mathrm{SO}_{4}$ aqueous solution $(\mathrm{pH} \approx 6.3)$.

\section{Supporting Information}

Supporting Information is available from the Wiley Online Library or from the authors.

\section{Acknowledgments}

This project has received funding from the European Research Council (ERC) under the European Union's Horizon 2020 Research and Innovation Programme (Grant Agreement No. 849068). This work was also financially supported by the joint Israel Science Foundation National Science Foundation of China (ISF-NSFC) grant No. 2969/19.

The authors would like to thank Adi Azoulay and Jonathan Tzadikov for help with material characterizations, and Nadav Aharon from the nano-fabrication center for technical support.

Received: ((will be filled in by the editorial staff))

Revised: ((will be filled in by the editorial staff)) Published online: ((will be filled in by the editorial staff))

\section{References}

[1] X. Wang, K. Maeda, A. Thomas, K. Takanabe, G. Xin, J. M. Carlsson, K. Domen, M. Antonietti, Nat. Mater. 2009, 8, 76.

[2] W. Niu, Y. Yang, ACS Energy Lett. 2018, 3, 2796.

[3] H. Li, B. Zhu, S. Cao, J. Yu, Chem. Commun. 2020, 56, 5641.

[4] J. Qin, S. Wang, H. Ren, Y. Hou, X. Wang, Appl. Catal., B 2015, 179, 1.

[5] K. Maeda, R. Kuriki, M. Zhang, X. Wang, O. Ishitani, J. Mater. Chem. A 2014, 2, 15146. 
[6] F. Goettmann, A. Fischer, M. Antonietti, A. Thomas, Chem. Commun. 2006, 4530.

[7] F. Su, S. C. Mathew, G. Lipner, X. Fu, M. Antonietti, S. Blechert, X. Wang, J. Am. Chem. Soc. 2010, 132, 16299.

[8] J. Barrio, M. Volokh, M. Shalom, J. Mater. Chem. A 2020, 8, 11075.

[9] Y. Fang, X. Fu, X. Wang, ACS Mater. Lett. 2020, 2, 975.

[10] S. Cao, J. Low, J. Yu, M. Jaroniec, Adv. Mater. 2015, 27, 2150.

[11] G. Dong, Y. Zhang, Q. Pan, J. Qiu, J. Photochem. Photobiol., C 2014, 20, 33.

[12] W.-J. Ong, L.-L. Tan, Y. H. Ng, S.-T. Yong, S.-P. Chai, Chem. Rev. 2016, 116, 7159.

[13] M. Volokh, G. Peng, J. Barrio, M. Shalom, Angew. Chem. Int. Ed. 2019, 58, 6138.

[14] X. Zou, Z. Sun, Y. H. Hu, J. Mater. Chem. A 2020, 8, 21474.

[15] W. Xiong, F. Huang, R.-Q. Zhang, Sustainable Energy Fuels 2020, 4, 485.

[16] Y. Zhang, Z. Zhou, H. Li, Appl. Phys. Lett. 1996, 68, 634.

[17] R. C. Dante, P. Martín-Ramos, A. Correa-Guimaraes, J. Martín-Gil, Mater. Chem. Phys. 2011, 130, 1094.

[18] X. Lv, M. Cao, W. Shi, M. Wang, Y. Shen, Carbon 2017, 117, 343.

[19] J. Bian, Q. Li, C. Huang, J. Li, Y. Guo, M. Zaw, R.-Q. Zhang, Nano Energy 2015, 15, 353.

[20] J. Bian, J. Li, S. Kalytchuk, Y. Wang, Q. Li, T. C. Lau, T. A. Niehaus, A. L. Rogach, R.-Q. Zhang, ChemPhysChem 2015, 16, 954.

[21] Q. Jia, S. Zhang, Z. Gao, P. Yang, Q. Gu, Catal. Sci. Technol. 2019, 9, 425.

[22] T. Zhao, Q. Zhou, Y. Lv, D. Han, K. Wu, L. Zhao, Y. Shen, S. Liu, Y. Zhang, Angew. Chem. Int. Ed. 2020, 59, 1139.

[23] J. Xu, I. Herraiz-Cardona, X. Yang, S. Gimenez, M. Antonietti, M. Shalom, Adv. Opt. Mater. 2015, 3, 1052.

[24] L. Abisdris, J. Tzadikov, N. Karjule, A. Azoulay, M. Volokh, M. Shalom, Sustainable Energy Fuels 2020, 4, 3879.

[25] G. H. Han, F. Güneş, J. J. Bae, E. S. Kim, S. J. Chae, H.-J. Shin, J.-Y. Choi, D. Pribat, Y. H. Lee, Nano Lett. 2011, 11, 4144.

[26] Q. Wu, J.-H. Park, S. Park, S. J. Jung, H. Suh, N. Park, W. Wongwiriyapan, S. Lee, Y. H. Lee, Y. J. Song, Sci. Rep. 2015, 5, 16159.

[27] X. Ling, Y.-H. Lee, Y. Lin, W. Fang, L. Yu, M. S. Dresselhaus, J. Kong, Nano Lett. 2014, 14, 464.

[28] K. Gilissen, J. Stryckers, P. Verstappen, J. Drijkoningen, G. H. L. Heintges, L. Lutsen, J. Manca, W. Maes, W. Deferme, Org. Electron. 2015, 20, 31.

[29] S. Bose, S. S. Keller, T. S. Alstrøm, A. Boisen, K. Almdal, Langmuir 2013, 29, 6911.

[30] K. Sivula, R. van de Krol, Nat. Rev. Mater. 2016, 1, 15010.

[31] J. Ran, H. Zhang, J. Qu, J. Shan, S. Chen, F. Yang, R. Zheng, J. Cairney, L. Song, L. Jing, S.-Z. Qiao, ACS Mater. Lett. 2020, 2, 1484.

[32] J. Ran, J. Qu, H. Zhang, T. Wen, H. Wang, S. Chen, L. Song, X. Zhang, L. Jing, R. Zheng, S.-Z. Qiao, Adv. Energy Mater. 2019, 9, 1803402.

[33] T. Yao, X. An, H. Han, J. Q. Chen, C. Li, Adv. Energy Mater. 2018, 8, 1800210.

[34] B. Xia, Y. Zhang, B. Shi, J. Ran, K. Davey, S.-Z. Qiao, Small Methods 2020, 4, 2000063.

[35] F.-M. Lee, L. E. Lahti, J. Chem. Eng. Data 1972, 17, 304.

[36] J. Xia, N. Karjule, L. Abisdris, M. Volokh, M. Shalom, Chem. Mater. 2020, 32, 5845.

[37] L. Ming, H. Yue, L. Xu, F. Chen, J. Mater. Chem. A 2014, 2, 19145.

[38] A. Mishra, A. Mehta, S. Basu, N. P. Shetti, K. R. Reddy, T. M. Aminabhavi, Carbon 2019, 149, 693.

[39] G. Peng, M. Volokh, J. Tzadikov, J. Sun, M. Shalom, Adv. Energy Mater. 2018, 8, 1800566 . 


\section{WILEY-VCH}

a)

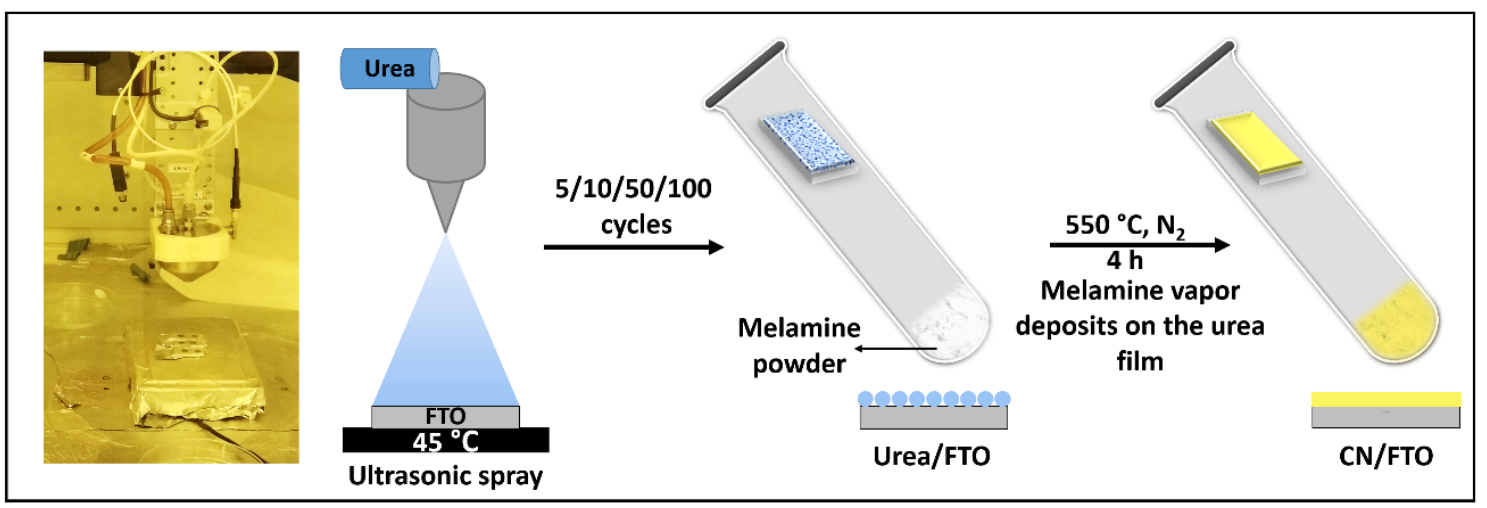

b)

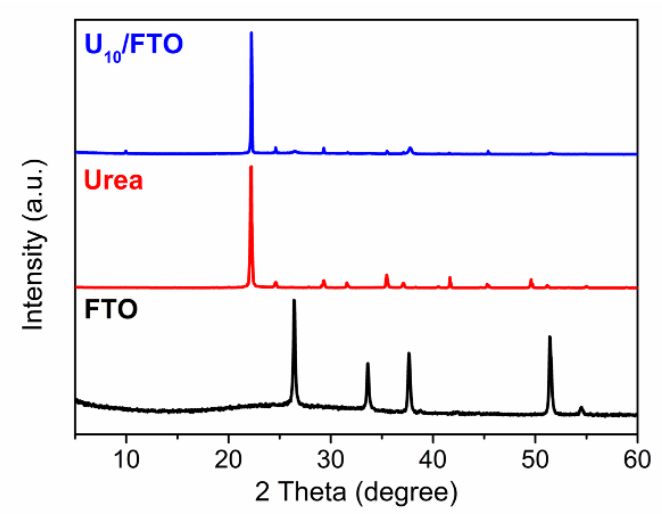

c)

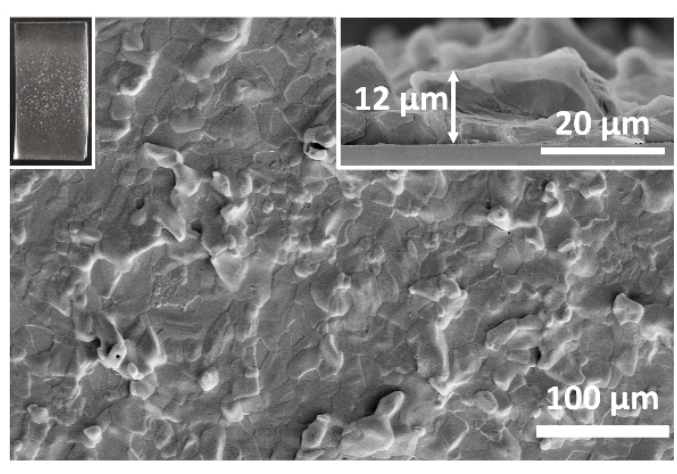

Figure 1. (a) Digital photo of the spray coater system (left); illustration of the preparation of $\mathrm{CN}$ films on FTO in two steps (right): spray coating of a $\mathrm{CN}$ precursor (urea) serving as a seeding layer, followed by calcination under an inert atmosphere in the presence of melamine powder in a glass tube. (b) XRD patterns of FTO (bottom, black), urea powder (middle, red), and $\mathrm{U}_{10}$ film on FTO (top, blue); the patterns are vertically offset for clarity. (c) Top-view SEM image of $U_{10}$ (insets: the corresponding digital photo and cross-sectional SEM image). 


\section{WILEY-VCH}

a)

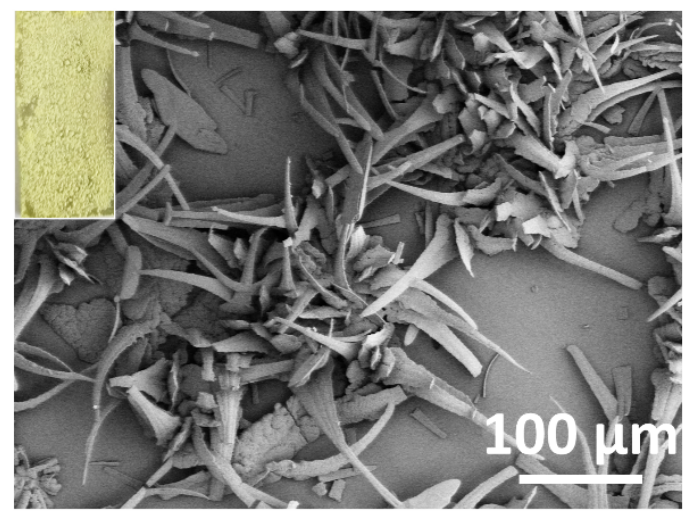

c)

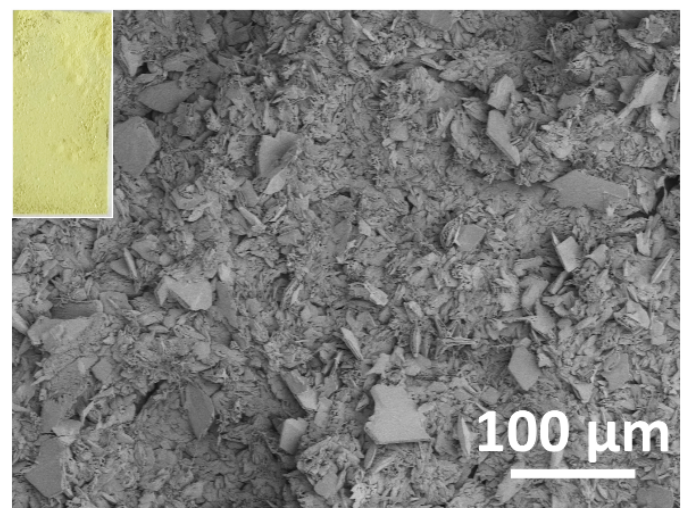

b)

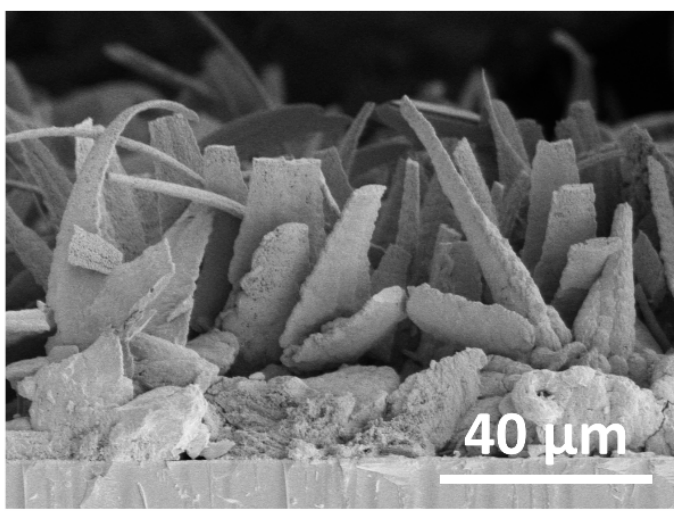

d)

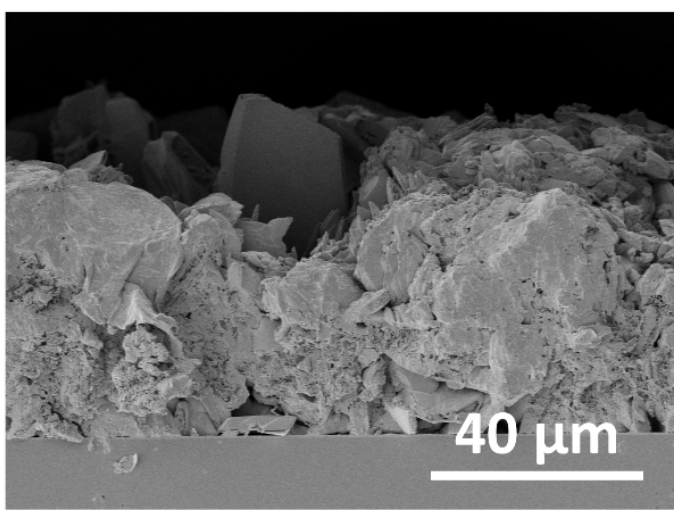

Figure 2. (a) Top-view (inset: digital photo) and (b) cross-sectional SEM images of CN-M $\mathrm{M}_{0.5}$.

(c) Top-view (inset: digital photo) and (d) cross-sectional SEM images of $\mathrm{U}_{10} \mathrm{M}_{0.5}$. 
WILEY-VCH
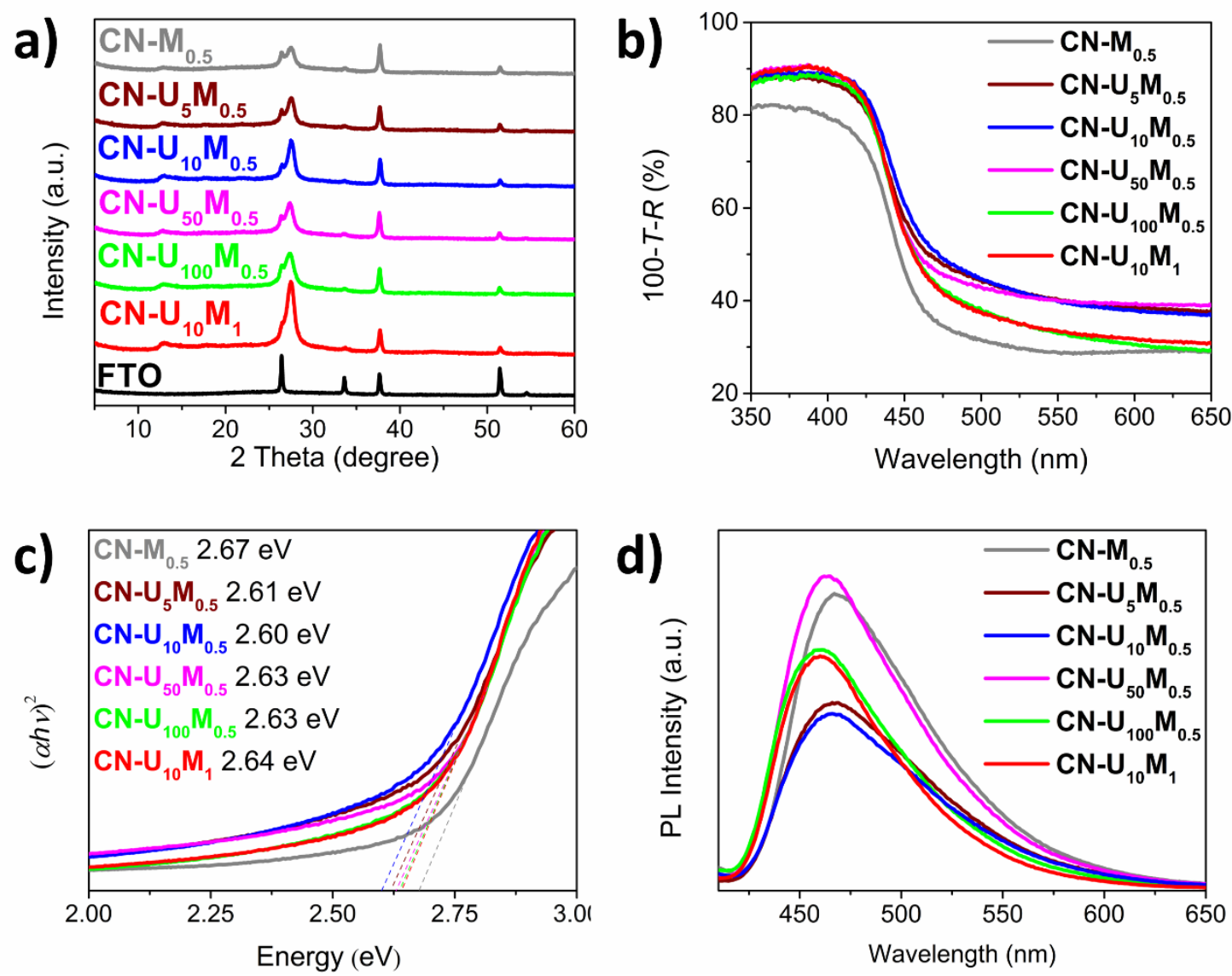

Figure 3. (a) XRD patterns of the $\mathrm{CN}$ electrodes; the diffraction signals at $26.4^{\circ}, 33.6^{\circ}, 37.7^{\circ}$, and $51.5^{\circ}$ are from the FTO substrate, and (bottom, black) diffraction pattern of a bare FTO substrate. (b) Absorbance spectra of the CN electrodes. (c) Tauc plot analysis for the determination of the optical band gaps of the CN electrodes. (d) PL spectra of the CN electrodes; $\lambda_{\mathrm{ex}}=390 \mathrm{~nm}$. 


\section{WILEY-VCH}
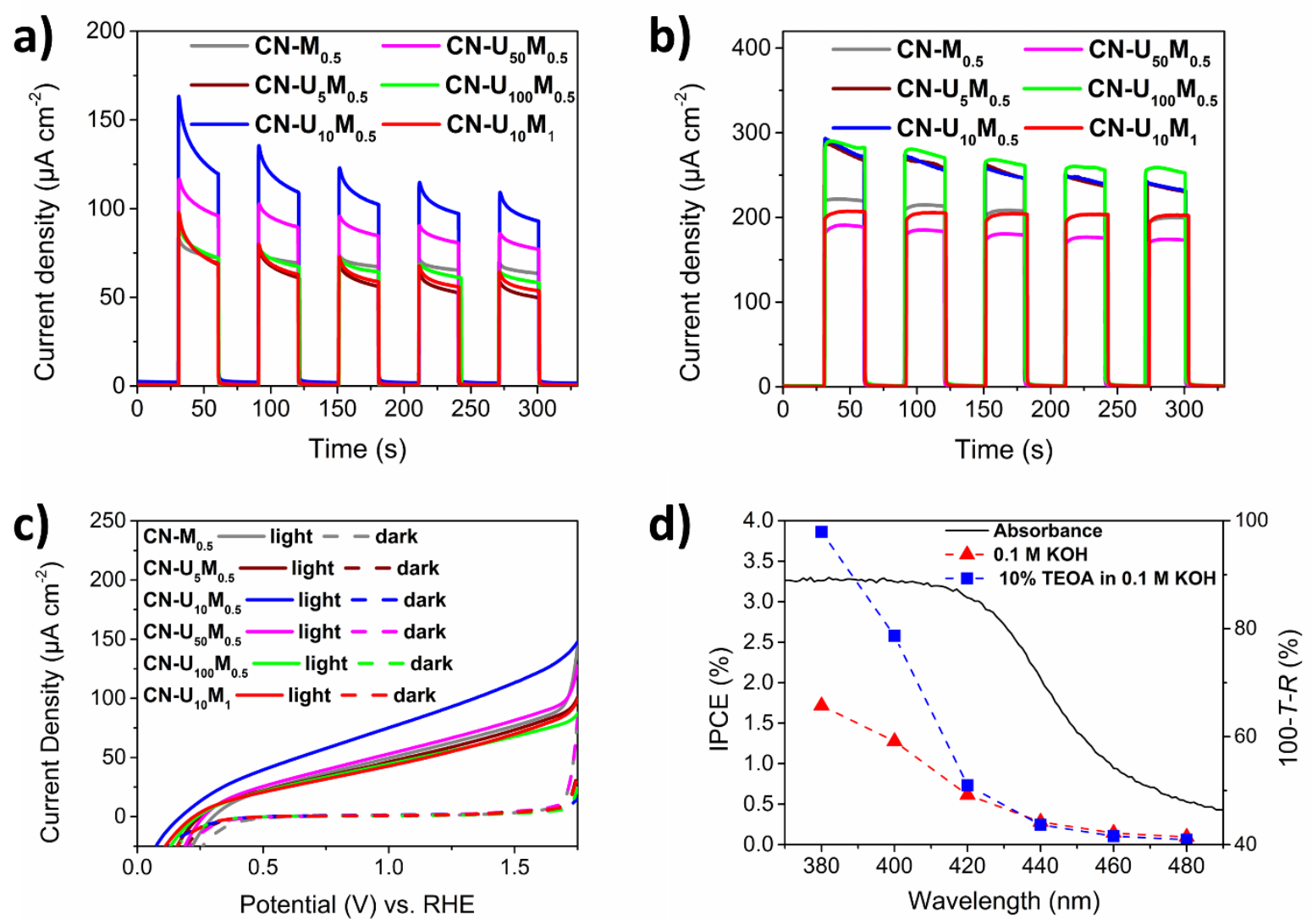

Figure 4. Characterization of PEC performance. Chronoamperometric measurements of CN electrodes (photocurrent density at $1.23 \mathrm{~V}$ vs. RHE) (a) in $0.1 \mathrm{M} \mathrm{KOH}$ and (b) in $0.1 \mathrm{M} \mathrm{KOH}$ aqueous solution containing $10 \%(\mathrm{v} / \mathrm{v})$ triethanolamine (TEOA) as a hole scavenger. (c) LSV curves of the $\mathrm{CN}$ electrodes; dashed lines — in the dark; complete lines - under illumination. (d) IPCE plots of CN-U ${ }_{10} \mathrm{M}_{0.5}$ at $1.23 \mathrm{~V} v s$. RHE in $0.1 \mathrm{M} \mathrm{KOH}$ and in $0.1 \mathrm{M} \mathrm{KOH}$ containing $10 \%$ TEOA (the experimental points are connected as a guide for the eye); the corresponding absorbance spectrum (black) of this photoelectrode is shown (absorbance \% values on the rightside $y$-axis). 
Ayelet Tashakory, Neeta Karjule, Liel Abisdris, Michael Volokh, Menny Shalom*

Mediated Growth of Carbon Nitride Films via Spray-Coated Seeding Layers for Photoelectrochemical Applications

A facile, large-scale growth of carbon nitride $(\mathrm{CN})$ layer on a substrate using spray-coated seeding layer is reported. Upon calcination in the presence of melamine vapor, a homogenous, thick CN layer with strong adhesion to the substrate is obtained. The CN films exhibit good performance as photoanodes in photoelectrochemical cells, with low onset potential, high photocurrent density, and moderate photostability.

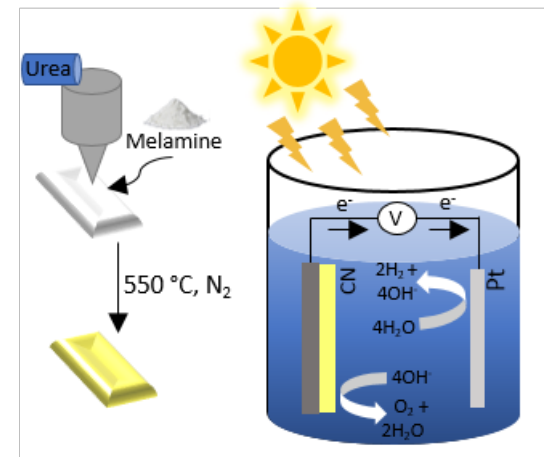




\section{WILEY-VCH}

Supporting Information

Mediated Growth of Carbon Nitride Films via Spray-Coated Seeding Layers for Photoelectrochemical Applications

Ayelet Tashakory, Neeta Karjule, Liel Abisdris, Michael Volokh, Menny Shalom*

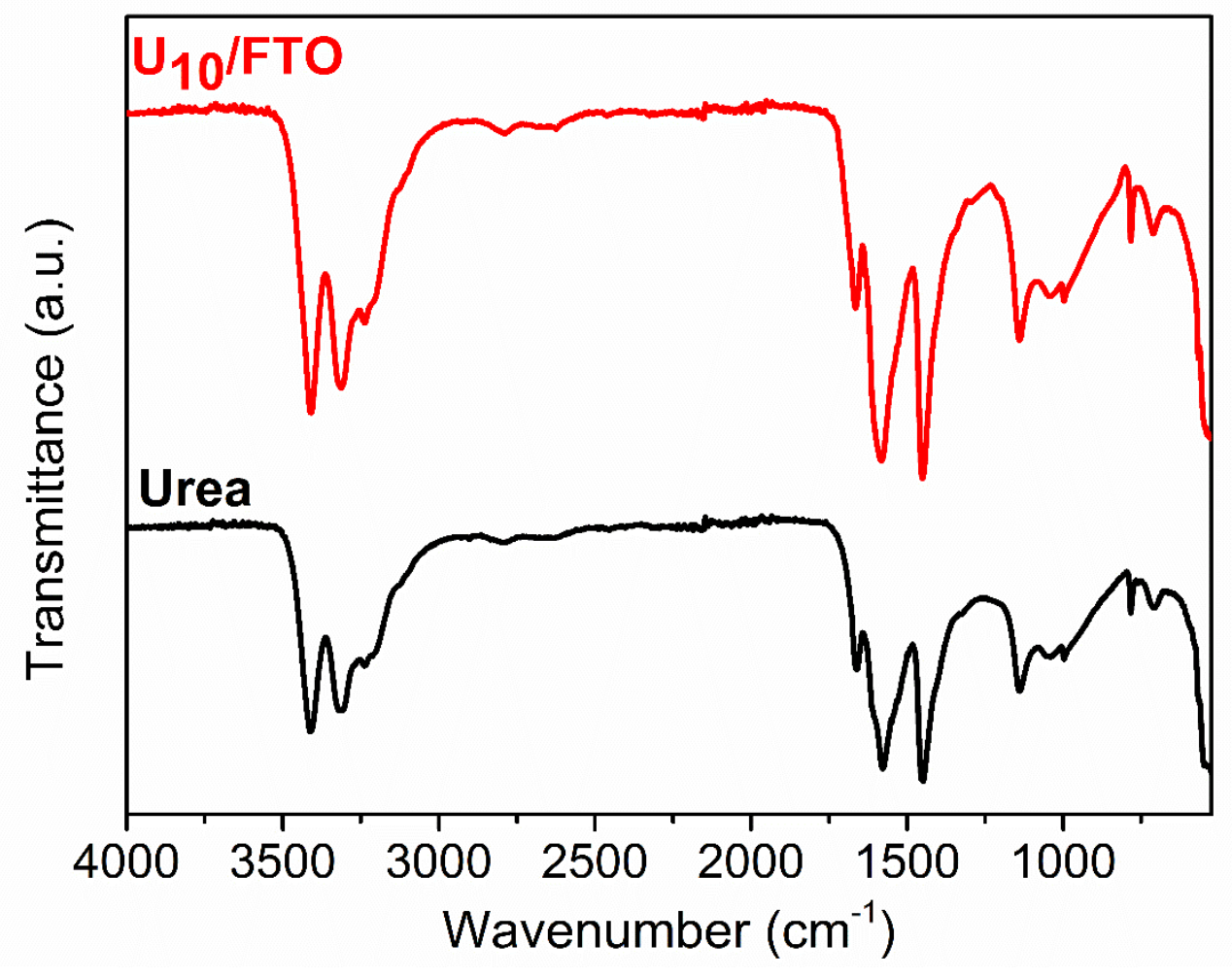

Figure S1. FTIR transmittance spectra of urea powder (bottom, black) and $\mathrm{U}_{10}$ film on FTO (top, red). Spectra are offset on the y-axis for clarity. 


\section{WILEY-VCH}

a)

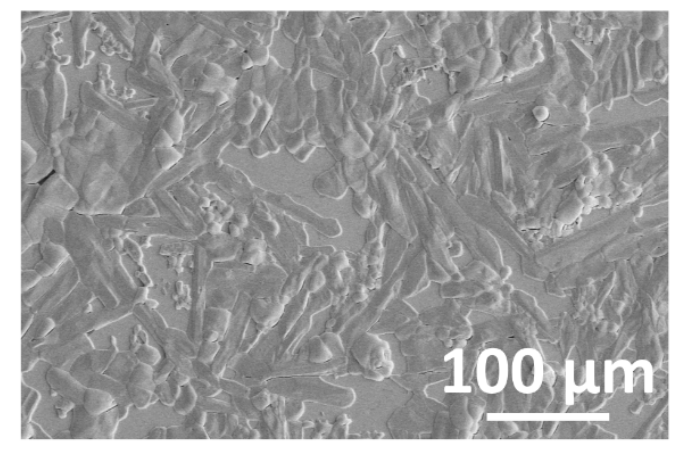

c)

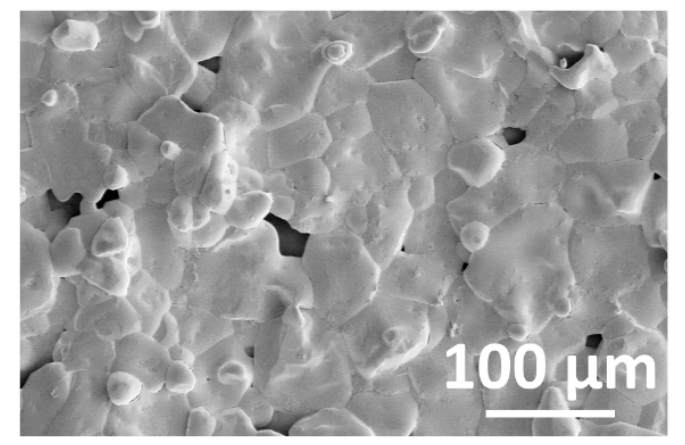

e)

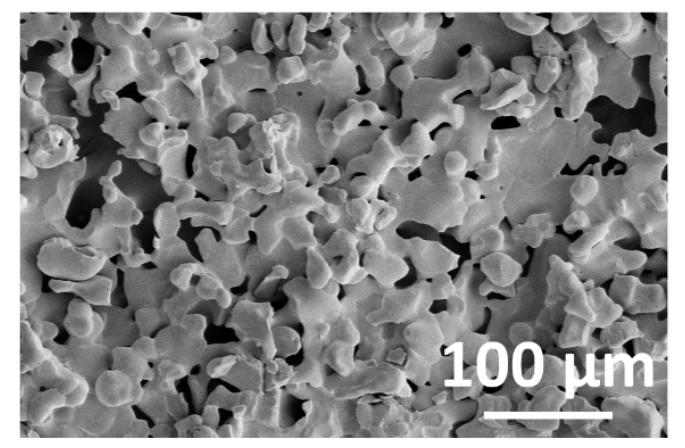

b)

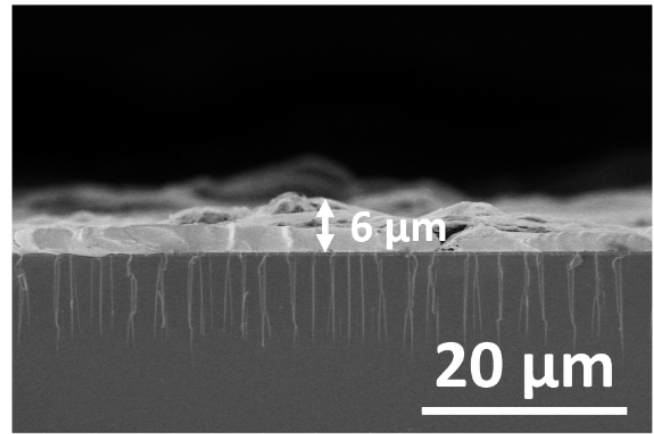

d)

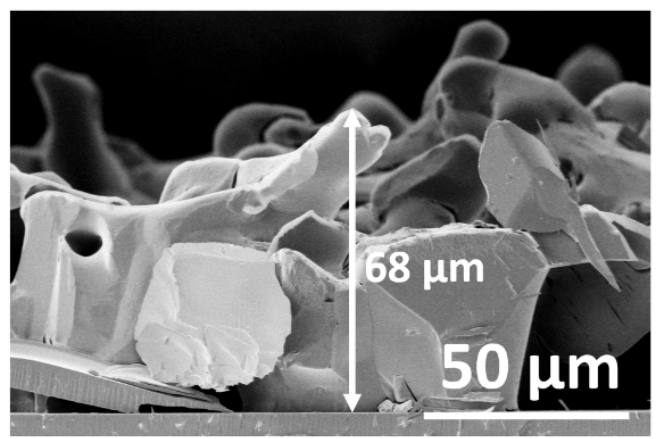

f)

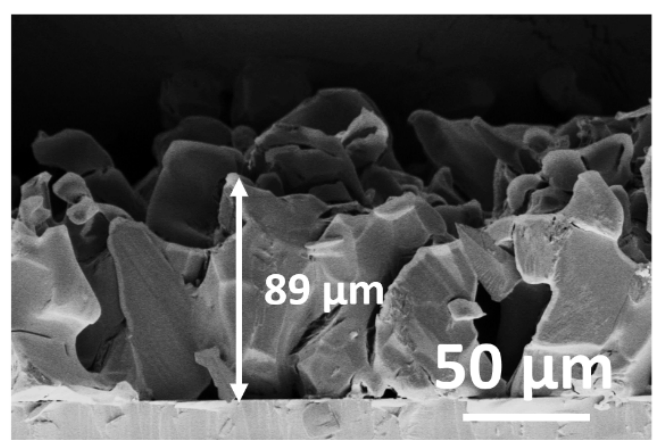

Figure S2. (a) Top-view and (b) cross-sectional SEM images of $U_{5}$; approximate height measurement of $6 \mu \mathrm{m}$. (c) Top-view and (d) cross-sectional SEM images of $U_{50}$; approximate height measurement of $68 \mu \mathrm{m}$. (e) Top-view and (f) cross-sectional SEM images of $\mathrm{U}_{100}$; approximate height measurement of $89 \mu \mathrm{m}$. 


\section{WILEY-VCH}

a)

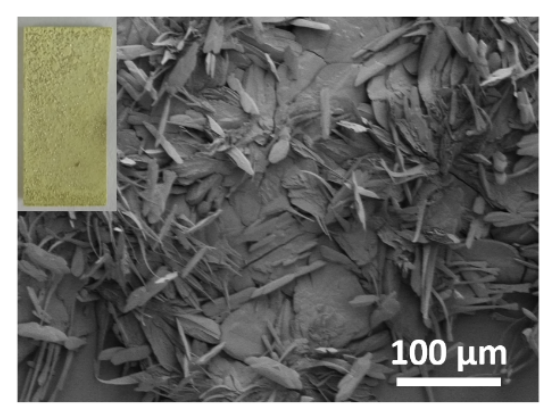

c)

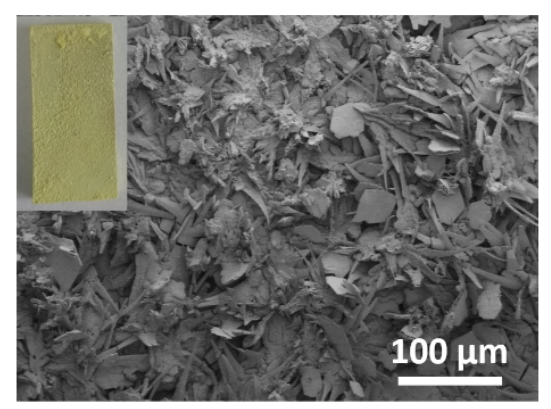

e)

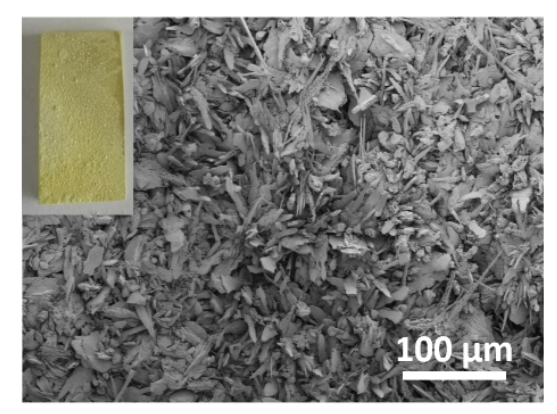

g)

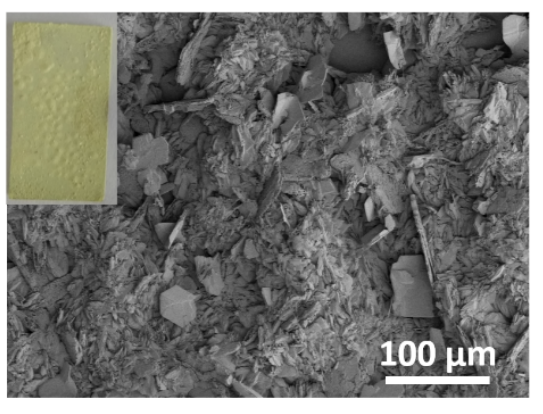

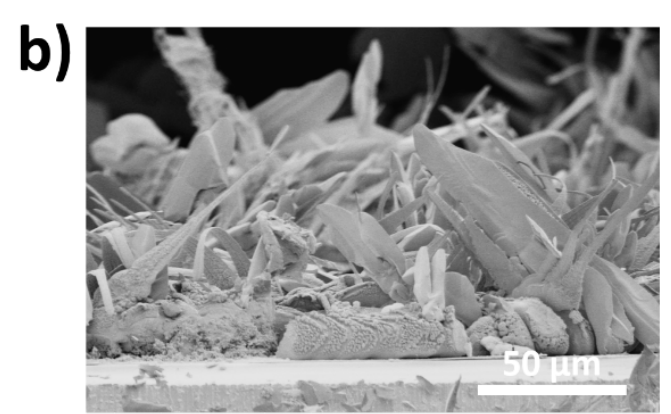

d)

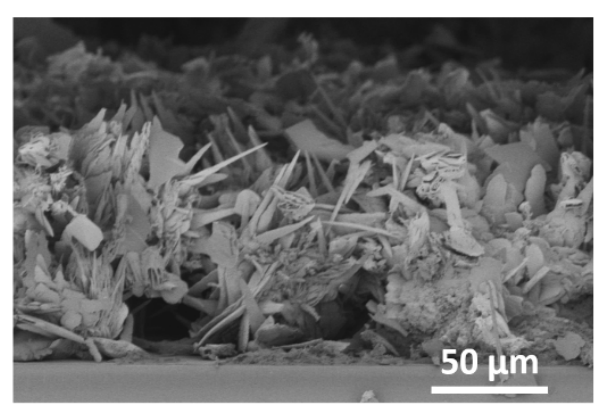

f)

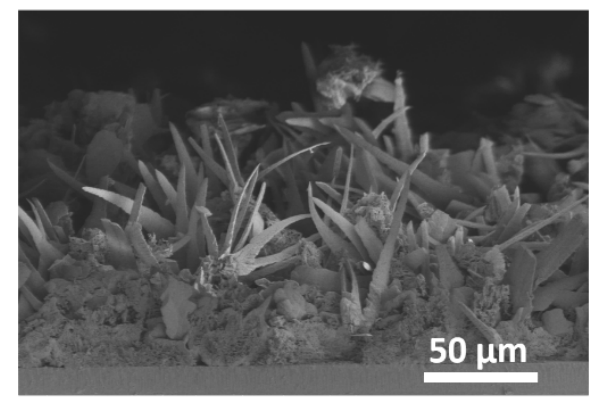

h)

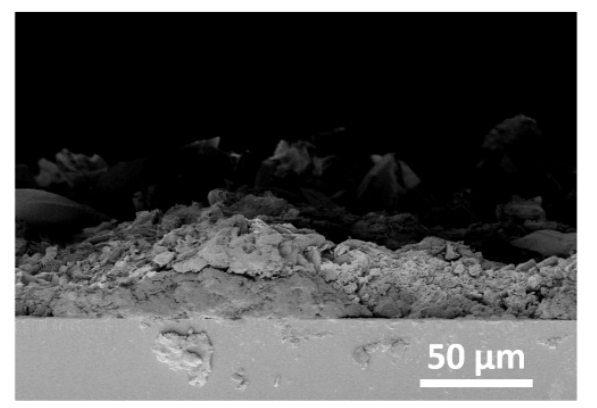

Figure S3. (a) Top-view SEM image of $\mathrm{CN}-\mathrm{U}_{5} \mathrm{M}_{0.5}$ (inset: digital photo). (b) Cross-sectional SEM image $\mathrm{CN}-\mathrm{U}_{5} \mathrm{M}_{0.5}$. (c) Top-view SEM image of $\mathrm{CN}-\mathrm{U}_{50} \mathrm{M}_{0.5}$ (inset: digital photo). (d) Cross-sectional SEM image of CN-U ${ }_{50} \mathrm{M}_{0.5}$. (e) Top-view SEM image of CN-U $\mathrm{U}_{100} \mathrm{M}_{0.5}$ (inset: digital photo). (f) Cross-sectional SEM image $\mathrm{CN}_{-} \mathrm{U}_{100} \mathrm{M}_{0.5}$. (g) Top-view SEM image of CN$\mathrm{U}_{10} \mathrm{M}_{1}$ (inset: digital photo). (h) Cross-sectional SEM image $\mathrm{CN}-\mathrm{U}_{10} \mathrm{M}_{1}$. 


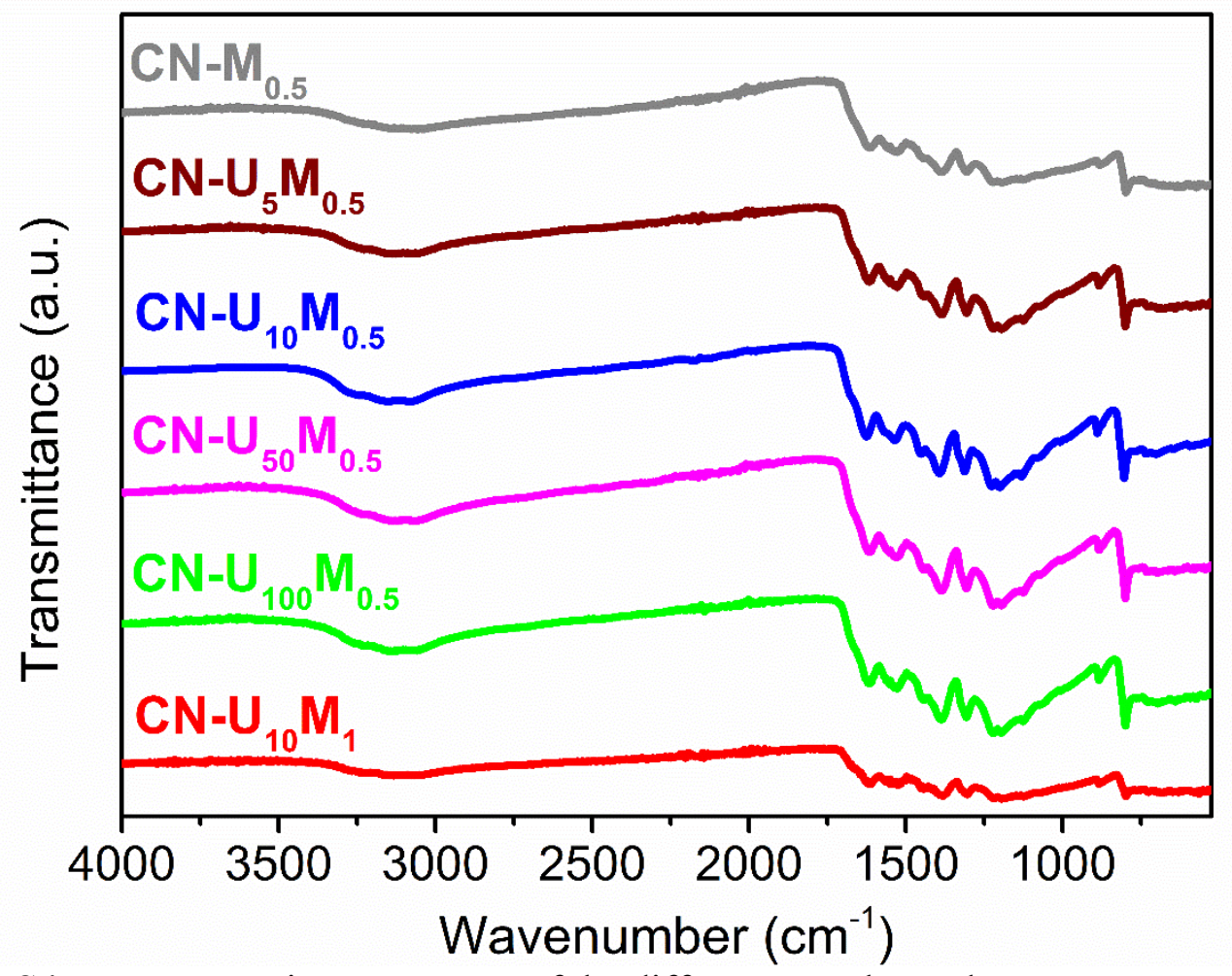

Figure S4. FTIR transmittance spectra of the different CN electrodes. Spectra are offset on the $y$-axis for clarity.

a)

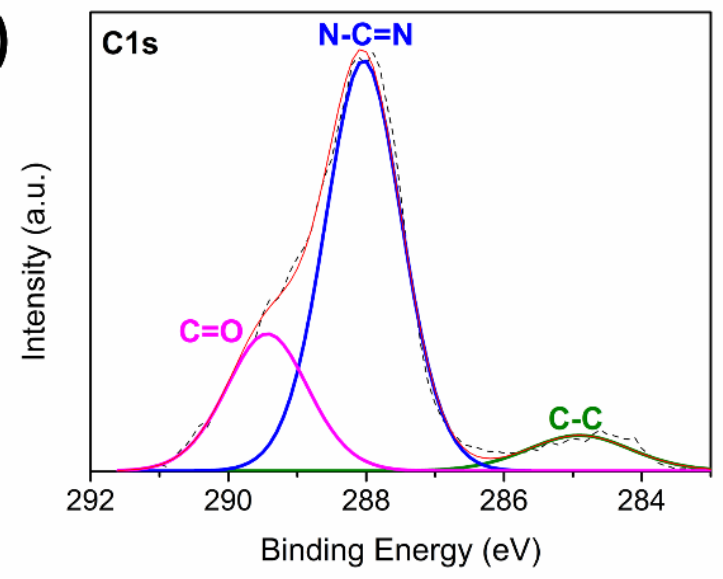

b)

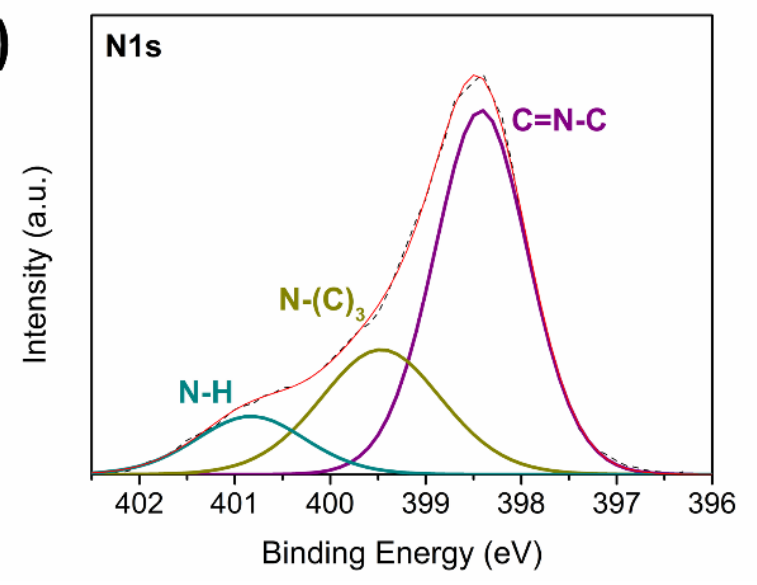

Figure S5. (a) $\mathrm{C} 1 \mathrm{~s}$ and (b) N1s XPS spectra of $\mathrm{CN}-\mathrm{U}_{10} \mathrm{M}_{0.5}$. Experimental signal: black dashed line; fitted signal: red curve; individual deconvoluted fitted spectra are shown using full colored traces. 


\section{WILEY-VCH}
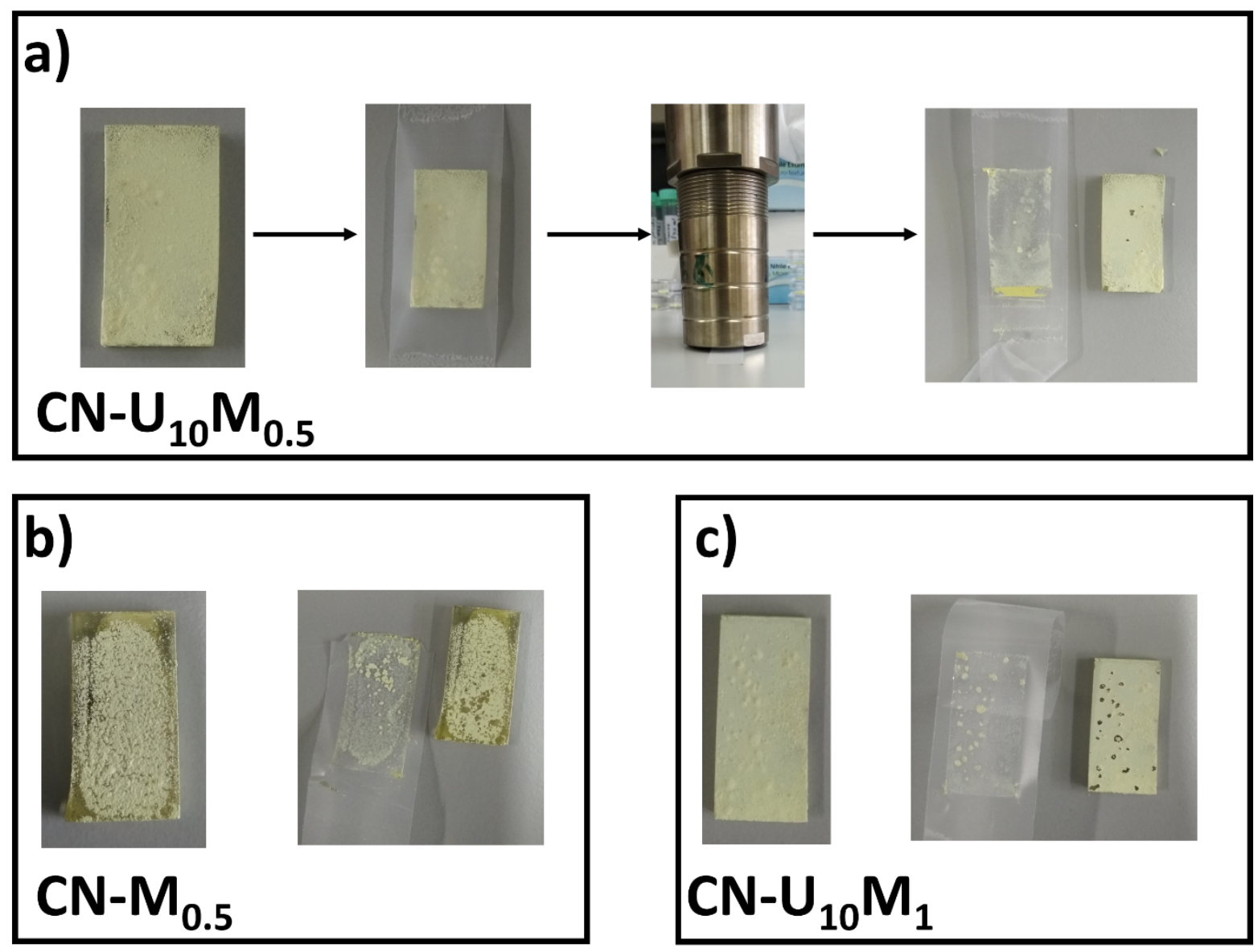

Figure S6. Adhesion tests. (a) Full adhesion test procedure for $\mathrm{CN}-\mathrm{U}_{10} \mathrm{M}_{0.5}$. (b) $\mathrm{CN}-\mathrm{M}_{0.5}$ and (c) $\mathrm{CN}-\mathrm{U}_{10} \mathrm{M}_{1}$ before (left) and after (right) the respective adhesion tests. 


\section{WILEY-VCH}
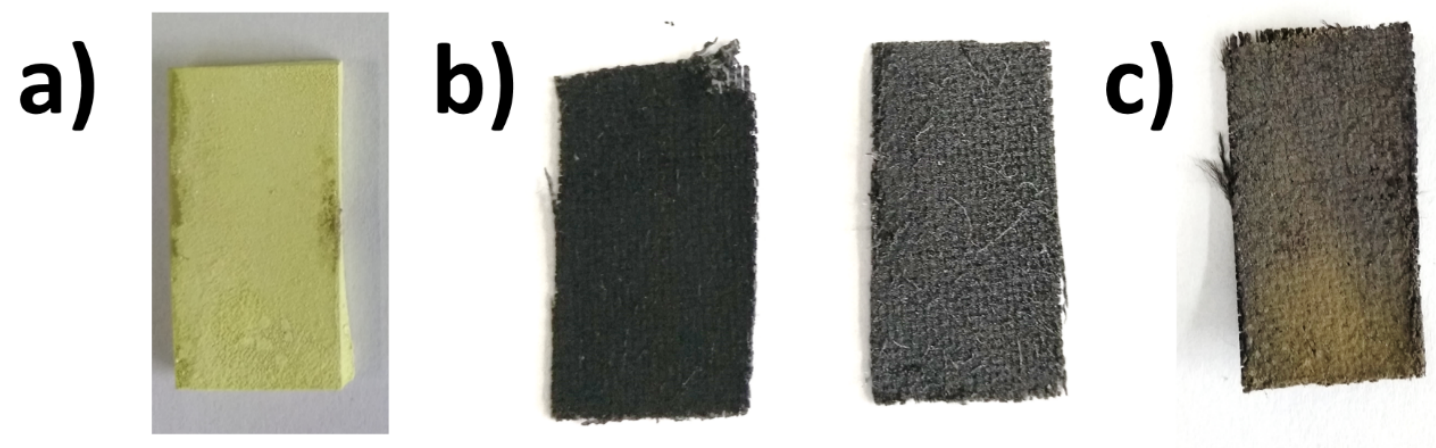

d)

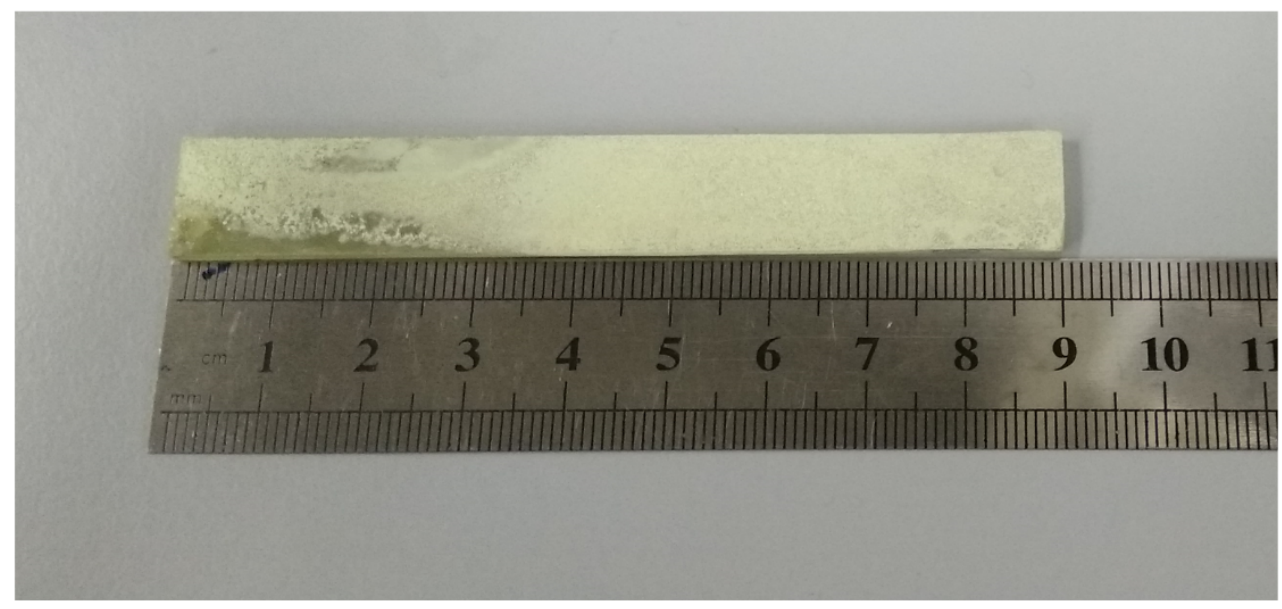

e)
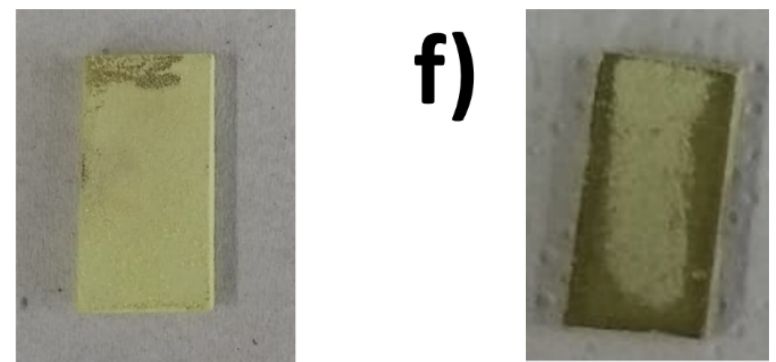

g)

Figure S7. CN films on various substrates and variation of the precursor. (a) $\mathrm{CN}-\mathrm{U}_{10} \mathrm{M}_{0.5}$ on a glass substrate (microscope slide). (b) clean carbon cloth (left) and $U_{10}$ deposited on carbon cloth (right). (c) The resulting $\mathrm{CN}-\mathrm{U}_{10} \mathrm{M}_{0.5}$ film on carbon cloth. (d) $\mathrm{CN}-\mathrm{U}_{10} \mathrm{M}_{1}$ deposited on an FTO with $9 \mathrm{~cm} \times 1.2 \mathrm{~cm}$ dimensions. $\mathrm{CN}$ electrodes formed by using (e) thiourea and (f) alanine as the seeding layer precursors, followed by calcination in the presence of melamine powder. (g) CN electrode prepared by using urea as a seeding layer, followed by calcination in the presence of thiourea powder (instead melamine in the standard procedure). 
a)

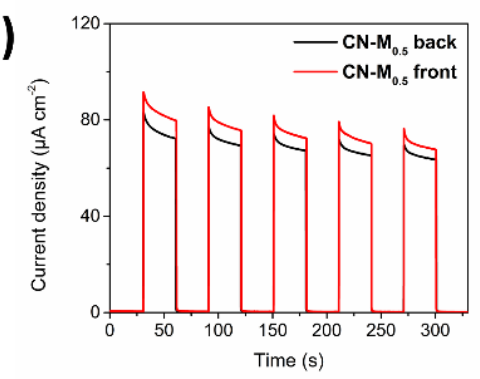

d)

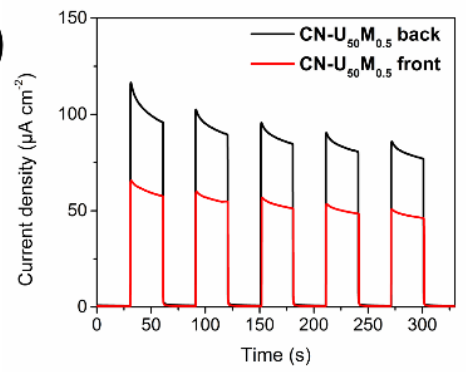

b)

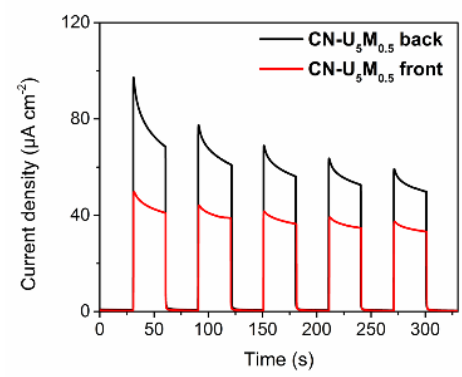

e)

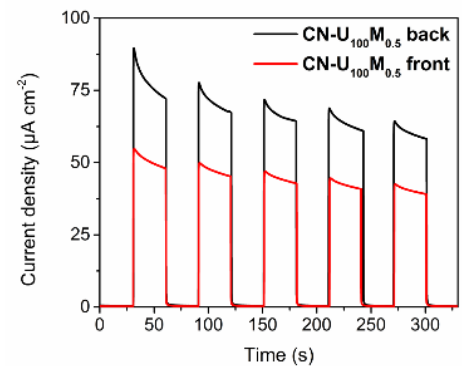

c)

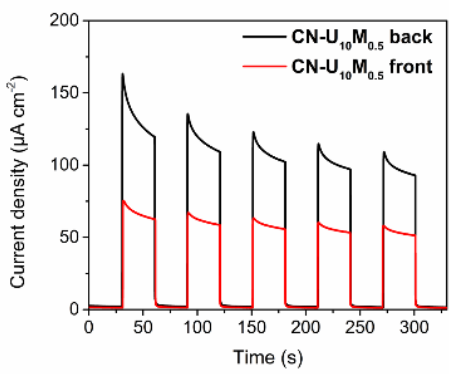

f)

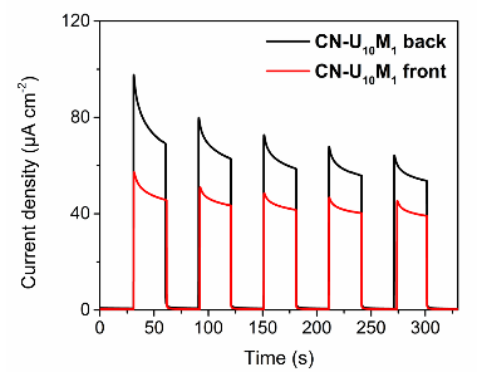

Figure S8. Chronoamperometric measurements (photocurrent densities at $1.23 \mathrm{~V}$ vs. RHE in $0.1 \mathrm{M} \mathrm{KOH}$ under front- and back-side illumination $v$ s. time) of (a) $\mathrm{CN}-\mathrm{M}_{0.5}$, (b) $\mathrm{CN}-\mathrm{U}_{5} \mathrm{M}_{0.5}$, (c) $\mathrm{CN}-\mathrm{U}_{10} \mathrm{M}_{0.5}$, (d) $\mathrm{CN}-\mathrm{U}_{50} \mathrm{M}_{0.5}$, (e) $\mathrm{CN}-\mathrm{U}_{100} \mathrm{M}_{0.5}$, and (f) $\mathrm{CN}-\mathrm{U}_{10} \mathrm{M}_{1}$.

a)

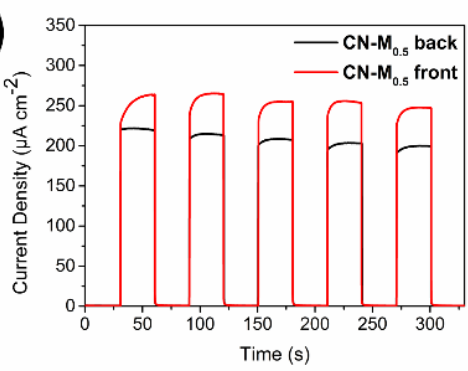

d)

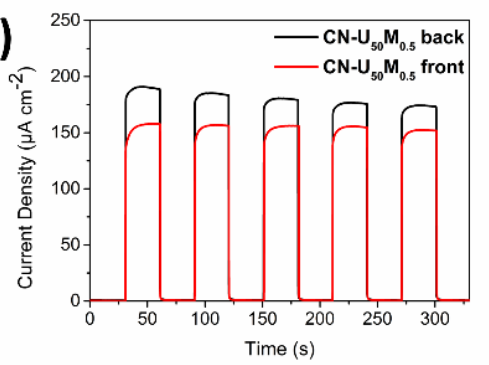

b)

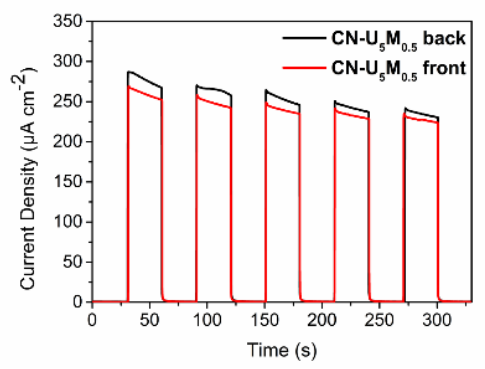

e)

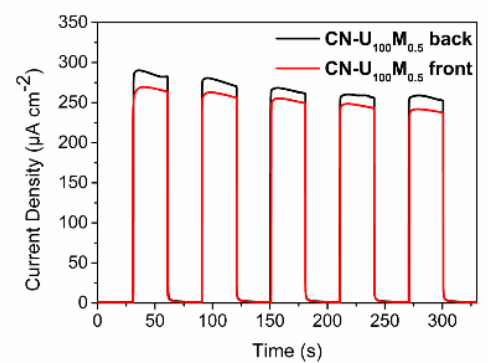

c)

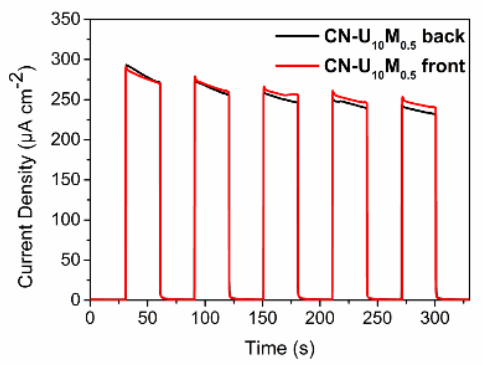

f)

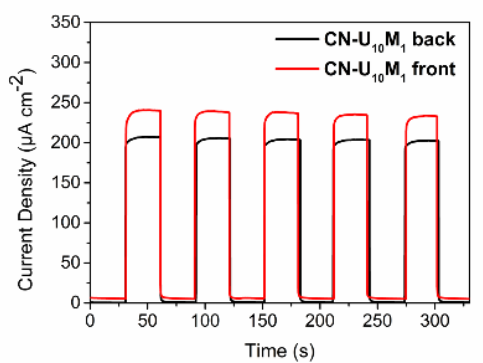

Figure S9. Chronoamperometric measurements in the presence of a hole scavenger (photocurrent densities at $1.23 \mathrm{~V} v s$. RHE in $0.1 \mathrm{M} \mathrm{KOH}$ containing $10 \%(\mathrm{v} / \mathrm{v})$ triethanolamine (TEOA) under front- and back-side illumination $v$ s. time) of (a) $\mathrm{CN}-\mathrm{M}_{0.5}$, (b) $\mathrm{CN}-\mathrm{U}_{5} \mathrm{M}_{0.5}$, (c) $\mathrm{CN}-\mathrm{U}_{10} \mathrm{M}_{0.5}$, (d) $\mathrm{CN}-\mathrm{U}_{50} \mathrm{M}_{0.5}$, (e) $\mathrm{CN}-\mathrm{U}_{100} \mathrm{M}_{0.5}$, and (f) $\mathrm{CN}-\mathrm{U}_{10} \mathrm{M}_{1}$. 


\section{WILEY-VCH}

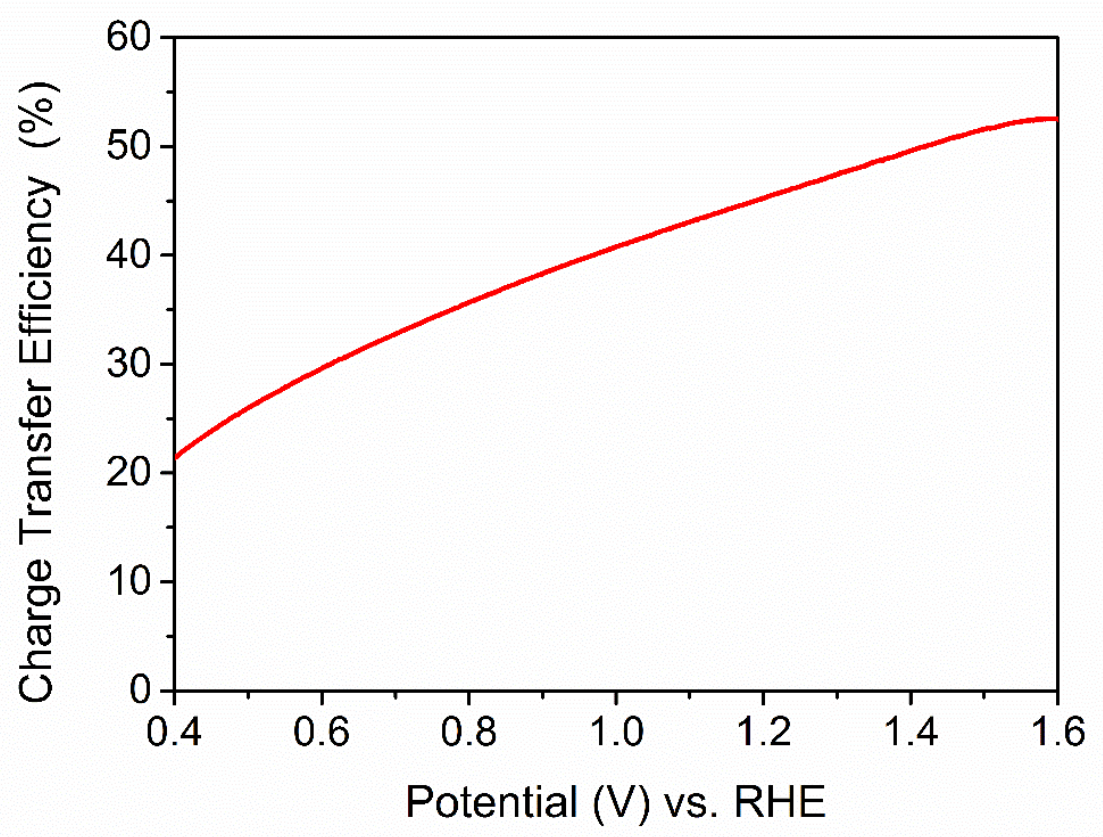

Figure S10. Calculated charge transfer efficiency of $\mathrm{CN}-\mathrm{U}_{10} \mathrm{M}_{0.5} v s$. applied potential.

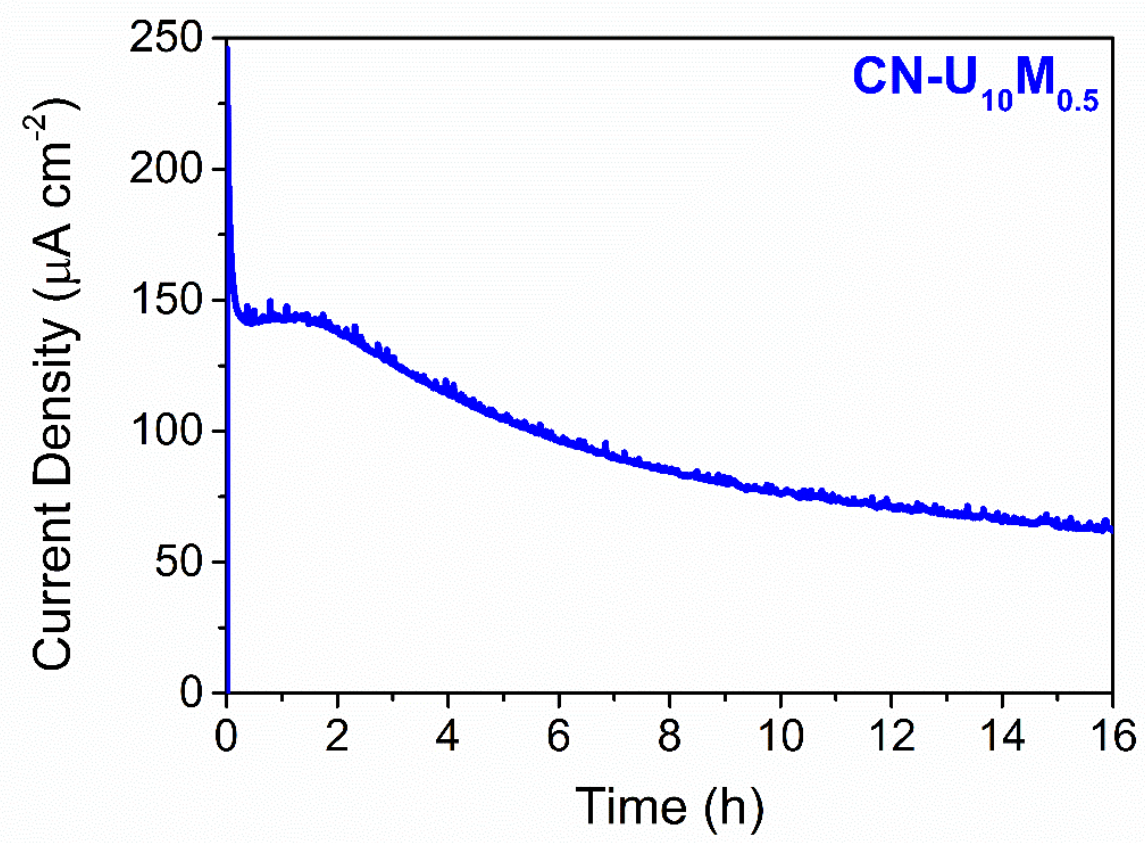

Figure S11. Photocurrent density of $\mathrm{CN}-\mathrm{U}_{10} \mathrm{M}_{0.5}$ at $1.23 \mathrm{~V}$ vs. RHE in $0.1 \mathrm{M} \mathrm{KOH}$ aqueous solution containing $10 \%$ TEOA under 16 hours of continuous 1-sun back-side illumination. 


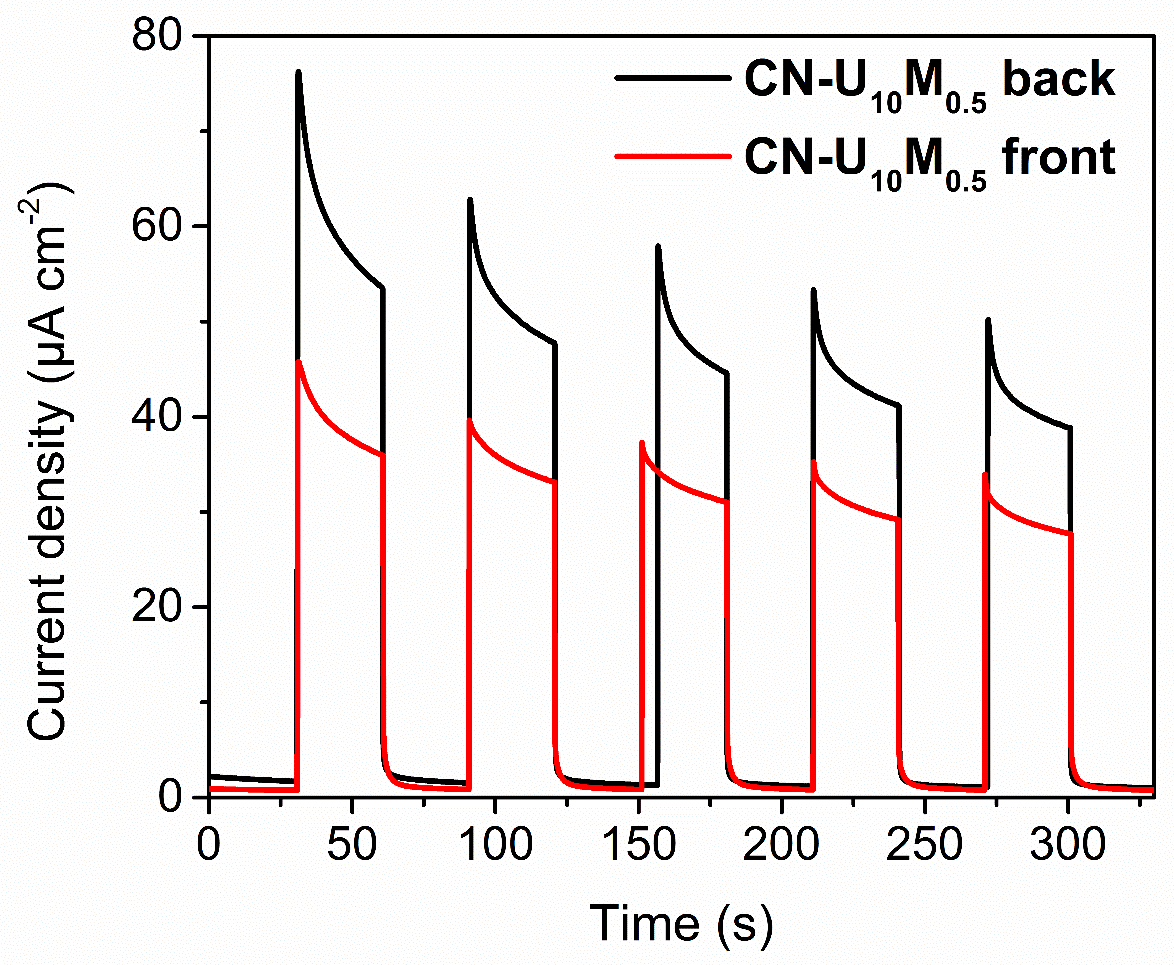

Figure S12. Chronoamperometric measurements (photocurrent densities at $1.23 \mathrm{~V} v s$. RHE in $0.1 \mathrm{M}$ sodium phosphate buffer solution, $\mathrm{pH} \sim 7$, under front- and back-side illumination $v s$. time) of $\mathrm{CN}-\mathrm{U}_{10} \mathrm{M}_{0.5}$.

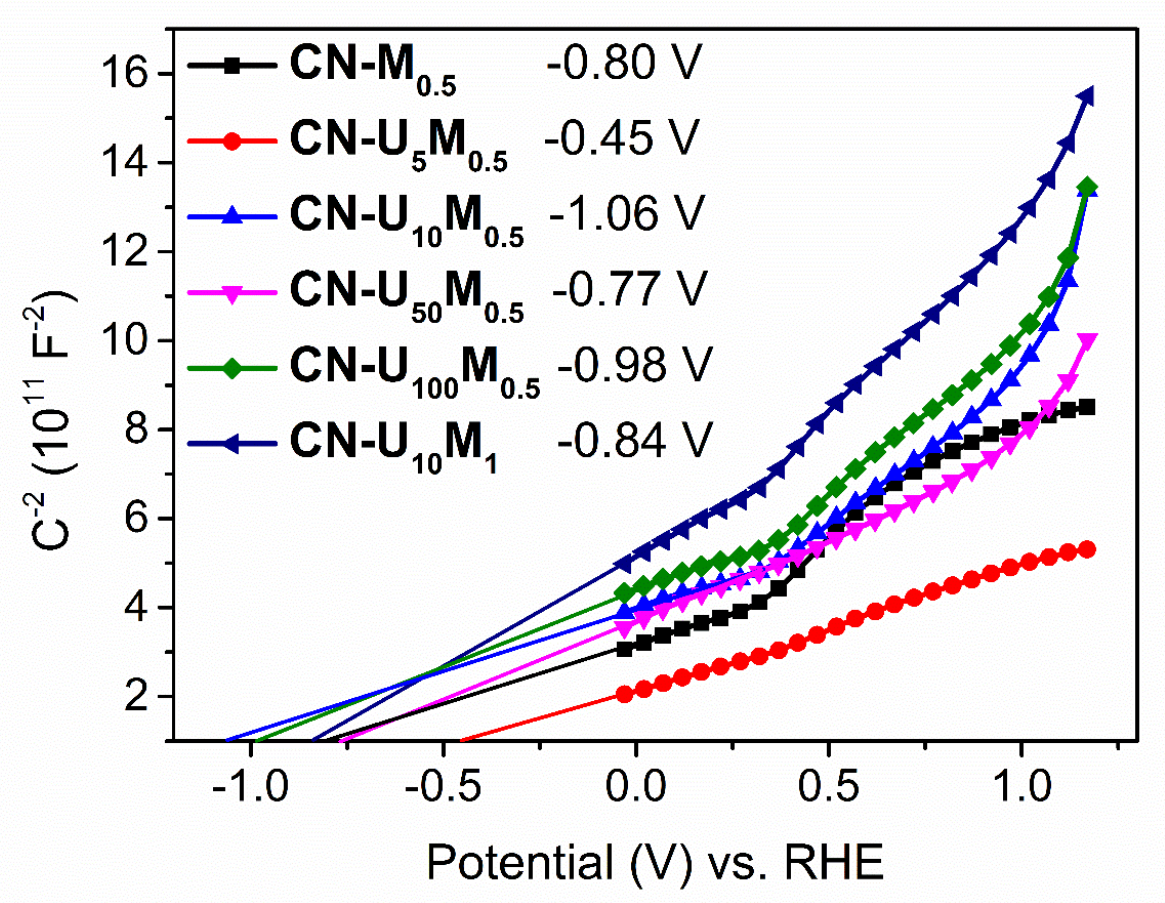

Figure S13. Mott-Schottky measurements of the CN electrodes. The determined CB positions are calculated using linear extrapolation and appear in the legend. 


\section{WILEY-VCH}

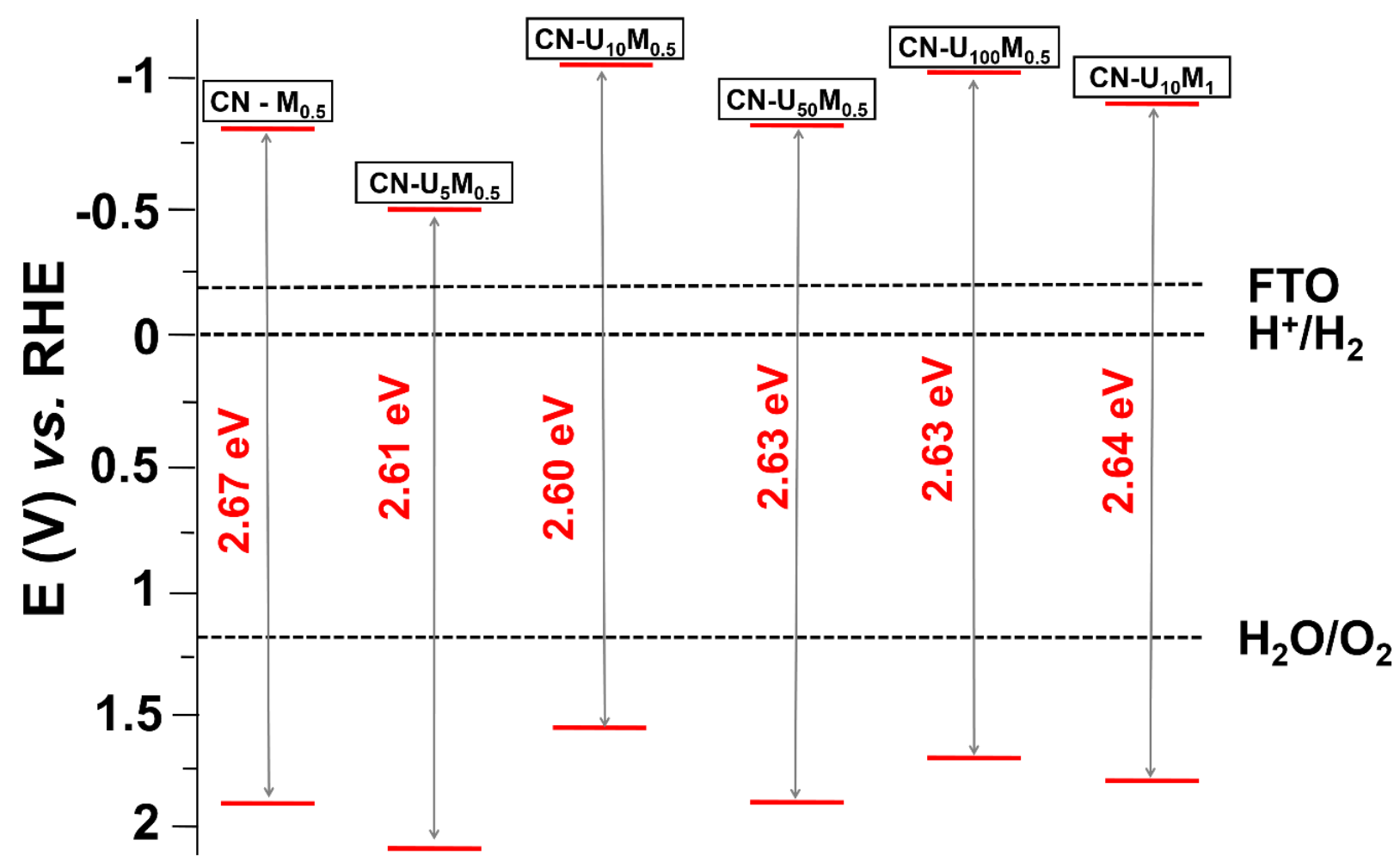

Figure S14. Calculated electronic energy band diagrams of the $\mathrm{CN}$ electrodes on the RHE scale (determined by Mott-Schottky analysis and the optical band gap).

a)

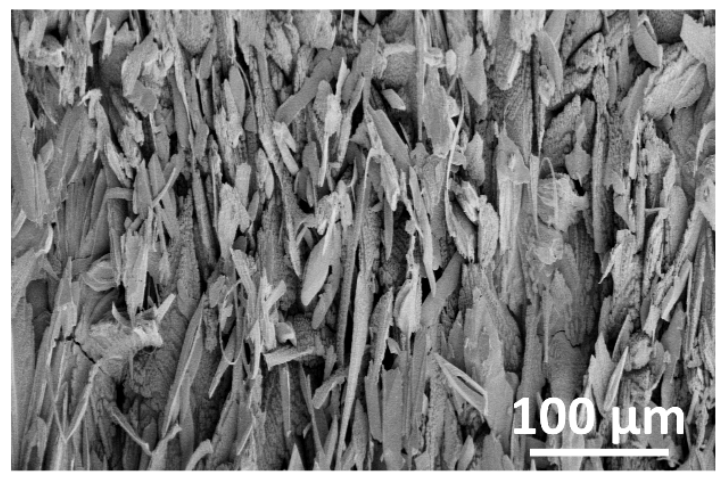

b)

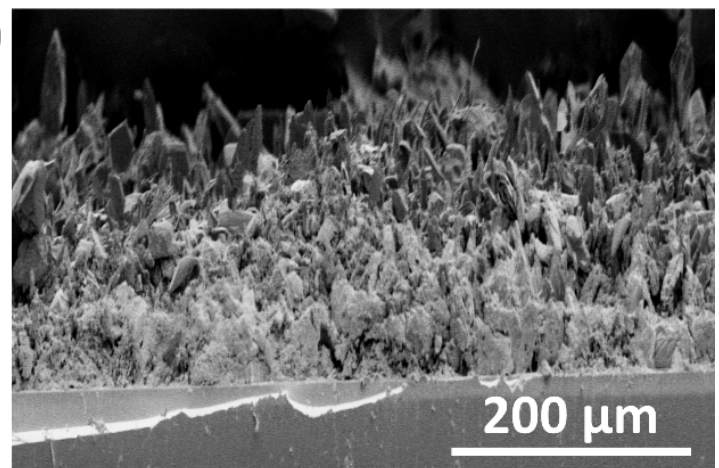

Figure S15. (a) Top-view and (b) cross-sectional SEM images of $\mathrm{CN}-\mathrm{U}_{10} \mathrm{M}_{0.5}$ post-PEC measurements. 


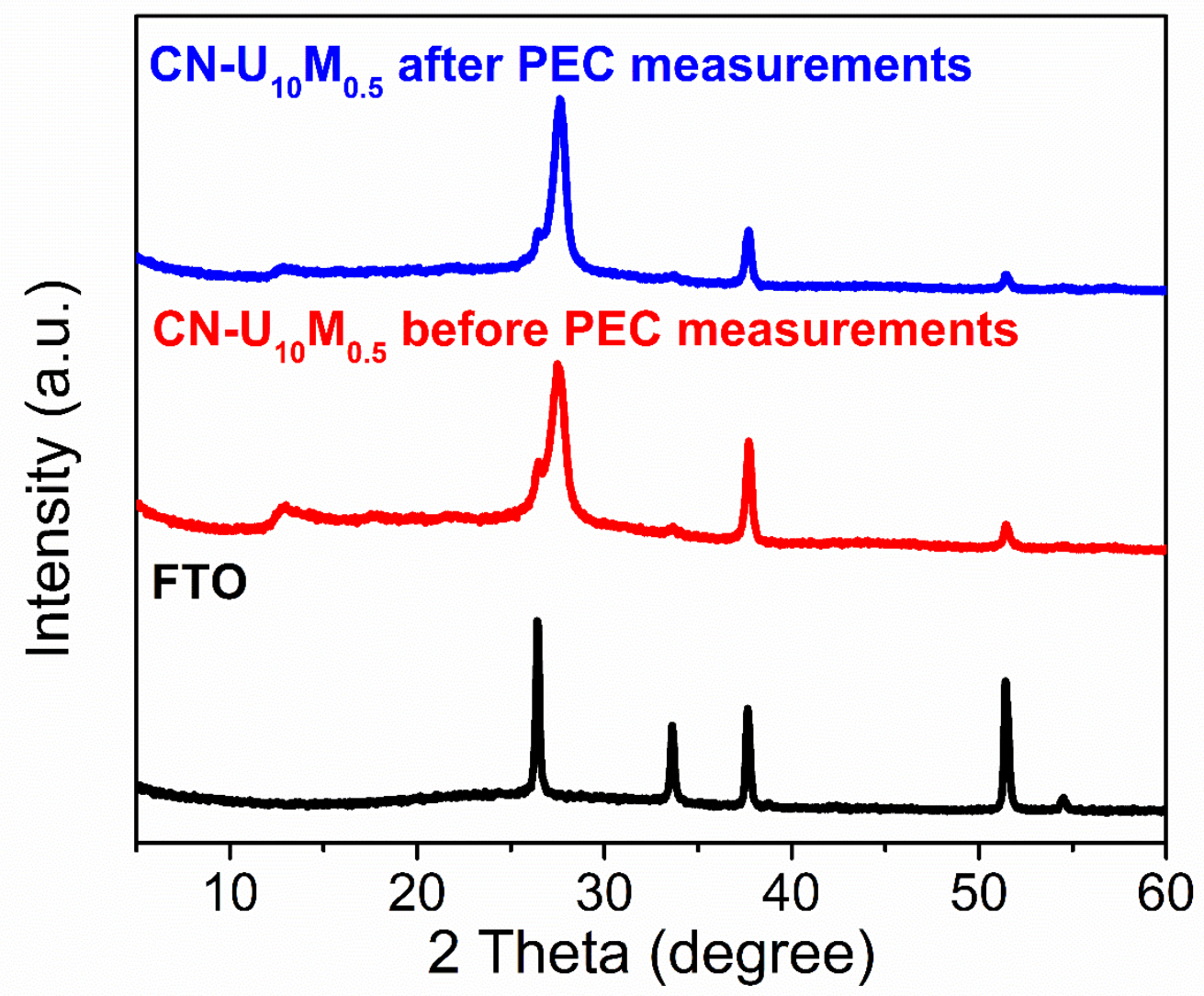

Figure S16. XRD patterns of FTO (bottom, black), $\mathrm{CN}-\mathrm{U}_{10} \mathrm{M}_{0.5}$ before PEC measurements (middle, red), and $\mathrm{CN}-\mathrm{U}_{10} \mathrm{M}_{0.5}$ after PEC measurements (top, blue); the patterns are vertically offset for clarity. 


\section{WILEY-VCH}

a)

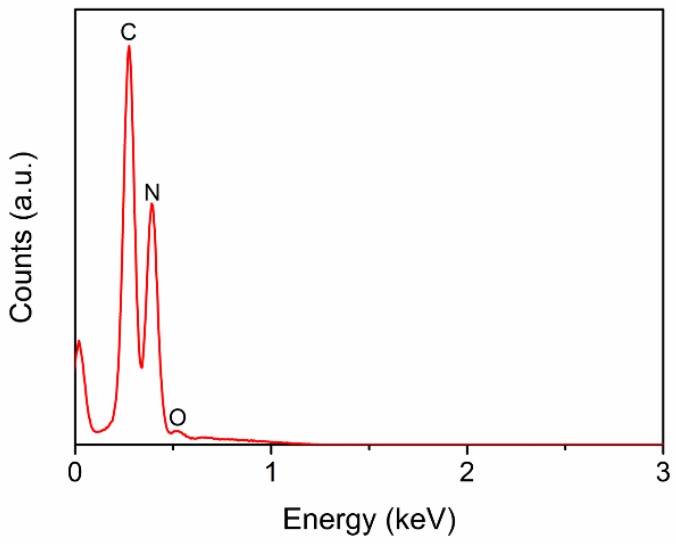

b)

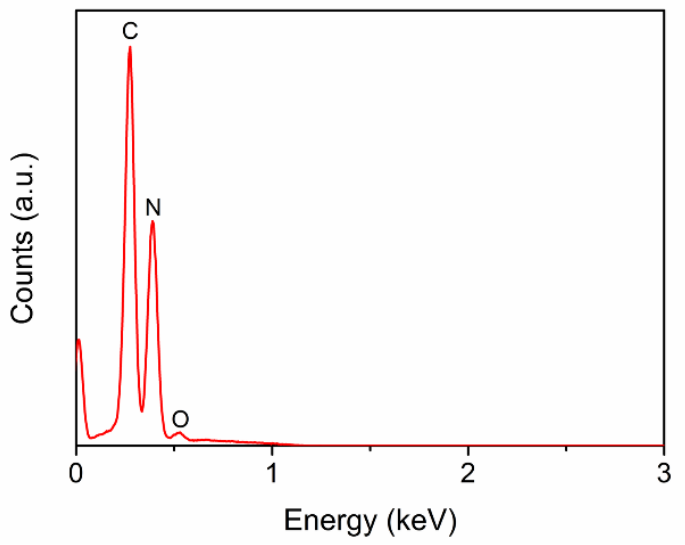

Figure S17. EDS spectra of CN-U ${ }_{10} \mathrm{M}_{0.5}$ film on FTO (a) before and (b) after PEC measurements.

Table S1. Elemental analysis of $\mathrm{CN}-\mathrm{U}_{10} \mathrm{M}_{0.5}$ obtained by SEM-EDS before and after PEC measurements.

\begin{tabular}{|c|c|c|}
\hline Element & Before PEC measurements (at. \%) & After PEC measurements (at. \%) \\
\hline $\mathrm{C}$ & $48.0 \pm 0.2$ & $47.2 \pm 0.2$ \\
\hline $\mathrm{N}$ & $51.7 \pm 0.2$ & $51.7 \pm 0.2$ \\
\hline $\mathrm{O}$ & $0.34 \pm 0.06$ & $1.08 \pm 0.06$ \\
\hline
\end{tabular}

